\title{
Antidiabetic Activity of Phytosynthesized Ag/CuO Nanocomposites Using Murraya Koenigii and Zingiber Officinale Extracts
}

\section{Arumai Selvan}

The New College (Autonomous), University of Madras

\section{R. Senthil Kumar}

Swamy Vivekanandha College of Pharmacy, Tiruchengode

\section{S. Shobana}

SRM Institute of Science and Technology, Kattankulathur

\section{S. Murugesan}

Paavendhar College of Arts \& Science, Attur

\section{A. kalilur Rahiman ( $\nabla$ akrahmanjkr@gmail.com )}

The New College (Autonomous), University of Madras https://orcid.org/0000-0002-0824-0493

\section{Original Research Full Papers}

Keywords: Murraya koenigii extract, Zingiber offıcinale extract, Antidiabetic activity, Glucose-6phosphatase activity, Glucose uptake assay

Posted Date: February 1st, 2021

DOl: https://doi.org/10.21203/rs.3.rs-163540/v1

License: (c) (1) This work is licensed under a Creative Commons Attribution 4.0 International License. Read Full License 


\title{
Antidiabetic Activity of Phytosynthesized Ag/CuO Nanocomposites Using Murraya koenigii and Zingiber officinale Extracts
}

\author{
D. Arumai Selvan ${ }^{1}$. R. Senthil Kumar ${ }^{2}$. S. Shobana ${ }^{3}$. S. Murugesan ${ }^{4}$. \\ A. Kalilur Rahiman ${ }^{1 *}$ \\ ${ }^{1}$ Post-Graduate and Research Department of Chemistry, The New College (Autonomous), \\ University of Madras, Chennai - 600 014, India \\ ${ }^{2}$ Department of Pharmaceutical Chemistry, Swamy Vivekanandha College of Pharmacy, \\ Tiruchengode - 637 205, India \\ ${ }^{3}$ Department of Genetic Engineering, School of Bioengineering, \\ SRM Institute of Science and Technology, Kattankulathur - 603 203, India \\ ${ }^{4}$ Department of Physics, Paavendhar College of Arts \& Science, Attur - 636 121, India \\ *E-mail address: akrahmanjkr@gmail.com
}

\begin{abstract}
In this paper, we report the phytosynthesis of $\mathrm{Ag} / \mathrm{CuO}$ nanocomposites ( $\mathrm{NCs}$ ) using Murraya koenigii and Zingiber officinale green extracts containing unique metabolites. The silver and copper oxide nanoparticles, and $\mathrm{Ag} / \mathrm{CuO} \mathrm{NCs}$ were also synthesized by chemical methods for the purpose of comparison with phytosynthesized $\mathrm{Ag} / \mathrm{CuO} \mathrm{NCs}$. All the synthesized nanomaterials were characterized by diverse spectro-analytical methods. The phytochemical analysis confirmed the presence of active phytoconstituents in the Murraya koenigii and Zingiber officinale extracts. The major biomolecules present in the plant extracts act as reducing and capping agents in the green synthesis process, as identified using FT IR spectroscopy. The maximum absorbance at $\sim 290$ and $\sim 460 \mathrm{~nm}$ corresponding to $\mathrm{CuO}$ and $\mathrm{Ag}$ evidenced the formation of $\mathrm{Ag} / \mathrm{CuO} \mathrm{NCs}$. Further, the XRD patterns also confirmed the formation of nanocomposites by exhibiting the fcc crystalline and monoclinic nature of $\mathrm{Ag}$ and $\mathrm{CuO}$ nanoparticles, respectively. The SEM images displayed the spherical shape of the synthesized NCs, and the EDX spectra confirmed the presence of $\mathrm{Ag}, \mathrm{Cu}$ and $\mathrm{O}$ elements in the synthesized NCs. The TEM images revealed the relatively uniform size of the synthesized
\end{abstract}


nanomaterials ranging between 18 and $22 \mathrm{~nm}$. The in vitro antidiabetic activity with $\alpha$ amylase, $\alpha$-glucosidase and glucose-6-phosphatase enzymes, and glucose uptake assay showed that the $\mathrm{Ag} / \mathrm{CuO} \mathrm{NCs}$ synthesized using Zingiber officinale extract displayed highest activity than the rest of the synthesized nanomaterials.

Keywords: Murraya koenigii extract - Zingiber officinale extract • Antidiabetic activity • Glucose-6-phosphatase activity • Glucose uptake assay

\section{Introduction}

In recent years, nanotechnology has gained wide-ranging interest due to its versatile properties and potential applications in modern material science. The wide scopes of research in various scientific disciplines are due to the unique properties of nanomaterials when compared with the bulk materials. The synthesis of nanomaterials through biological routes have attracted much attention in modern nanotechnology due to their unique advantages such as simple, scalable and non-toxic process, and improved biomedical applications $[1,2]$. In this connection, the metal and metal oxide nanoparticles are picking up more consideration because of their surface plasmonic properties and potential technological application in biomedical fields, sensors and photocatalysis [3]. The development of nanomaterials in biological and medicinal research leads to be strong strategies to control medical issues coupled with several diseases and infections.

Nowadays, distinctive combination of nanomaterials has attracted researchers due to their stability and versatile behaviour in which the synthesis and application of metal/metal oxide nanocomposites have gained much importance as the combination of two nanomaterials provide a distinctive model for the production of nanomaterials with specified properties $[4,5]$. Copper oxide $(\mathrm{CuO})$, a p-type semiconductor with a narrow bandgap of $1.2-$ 
$1.9 \mathrm{eV}$ and monoclinic crystal structure is well-known for diverse practical applications in heterogeneous catalysis, sensors, lithium ion electrode materials, field-emission sources, semiconductors etc., The combination of $\mathrm{CuO}$ with noble metal is an energizing area of research due to their enhanced biomedical, electronic, photocatalytic and other applications. For example, in the case of $\mathrm{CuO}$ decorated $\mathrm{Ag}$ nanoparticles, the charge transfer occurred from the $\mathrm{CuO}$ to the $\mathrm{Ag}$ nanoparticles, suppressing the recombination of charge carriers, and thus exhibiting the efficient photocatalytic properties [6-9]. Additionally, the $\mathrm{CuO}$ nanoparticles are stable and have longer shelf-life due to which it can be utilized for many therapeutic applications [10].

Among the several green synthesis sources, the plant extracts have attracted much attention because of their advantages such as abundant availability, safe to handle, and healing as well as curing of human diseases due to the presence of various metabolites. The active biomolecules present in the plant extracts also played a crucial role in the reduction process during the synthesis of nanomaterials. Murraya koenigii from Rutaceae family, generally called curry leaves having a slight pungent taste and used as flavouring agent in food items. It is also used in Siddha medicine as tonic for stomach ache, as stimulant and carminative, hypoglycemic agent, antifungal agent, and also exhibit anticancer activity against colon cancer [11, 12]. Zingiber officinale is a flowering plant belongs to Zingiberaceae family, whose rhizome, ginger root is widely used for remedial purposes over 2000 years in folk medicine [13].

The present study was designed to synthesize $\mathrm{Ag} / \mathrm{CuO}$ NCs using Murraya koenigii and Zingiber officinale extracts. The preliminary qualitative and quantitative phytochemical analysis was carried out for Murraya koenigii and Zingiber officinale extracts in order to identify and quantify their phytochemical constituents. The antidiabetic potential of the synthesized $\mathrm{Ag} / \mathrm{CuO} \mathrm{NCs}$ were assessed against $\alpha$-amylase, $\alpha$-glucosidase and glucose-6- 
phosphatase enzymes. The gulucose uptake activity of the synthesized $\mathrm{Ag} / \mathrm{CuO} \mathrm{NCs}$ were also analysed using 3T3-L1 preadipocyte cells.

\section{Experimental methods}

\subsection{Materials and methods}

Analytical grade silver nitrate was obtained from SD Fine Chemicals Limited (SDFCL), India. Copper acetate tetrahydrate, ethanol and sodium hydroxide were purchased from Fisher Scientific, India. 3T3-L1 preadipocyte cells were obtained from Microbial Type Culture Collection Center (MTCC), Chandigarh, India. Murraya koenigii and Zingiber officinale were acquired from nearby market, Royapettah, Chennai. The detailed procedure for the synthesis of silver and copper oxide nanoparticles are given in our earlier publications $[14,15]$. The $\mathrm{Ag} / \mathrm{CuO} \mathrm{NCs}$ were successfully synthesized using the plant extracts and chemical method by adopting the reported procedures with slight modifications $[16,17]$.

\subsection{Synthesis of $\mathrm{Ag} / \mathrm{CuO}$ nanocomposites ( $\mathrm{Ag} / \mathrm{CuO} \mathrm{NCs})$}

\subsubsection{Synthesis of $\mathrm{Ag} / \mathrm{CuO} \mathrm{NC}$ by chemical method}

Copper acetate tetrahydrate $(0.2 \mathrm{~mol})$ and equimolar sodium hydroxide were dissolved slowly in deionized water, and stirred for $1 \mathrm{~h}$ at $80{ }^{\circ} \mathrm{C}$ during which a black coloured precipitate was formed, indicating the formation of $\mathrm{CuO}$ nanoparticles. Then, silver nitrate $(0.42 \mathrm{~g}, 0.025 \mathrm{~mol})$ was added, and the mixture was stirred for $2 \mathrm{~h}$ at $80{ }^{\circ} \mathrm{C}$. The final product was collected by centrifugation at $500 \mathrm{rpm}$, washed with ethanol followed by deionized water, and dried in a hot air oven for $2 \mathrm{~h}$ at $120^{\circ} \mathrm{C}$.

\subsubsection{Synthesis of Ag/CuO NCs using Murraya koenigii and Zingiber officinale extracts}

$\mathrm{Ag} / \mathrm{CuO}$ NCs were synthesized by green method using Murraya koenigii and Zingiber officinale extracts. Murraya koenigii leaves were thoroughly washed with deionized water and air dried at room temperature. $10 \mathrm{~g}$ of air dried leaves were gauged and boiled at $100{ }^{\circ} \mathrm{C}$ with $250 \mathrm{~mL}$ of deionized water for $15 \mathrm{~min}$. The greenish extract was separated from the 
leaves using Whatman No.1 filter paper, and stored in refrigerator. Zingiber officinale was washed multiple times with deionized water to remove surface contaminations. The green extract was prepared by boiling $6 \mathrm{~g}$ of Zingiber officinale in $50 \mathrm{~mL}$ of deionized water and kept at normal room temperature for $24 \mathrm{~h}$. The resulting solution was decanted to remove solid pieces, filtered through Whatman No. 1 filter paper and stored in refrigerator.

Copper acetate tetrahydrate $(0.2 \mathrm{M})$ was dissolved in deionized water $(15 \mathrm{~mL})$ and silver nitrate $(0.42 \mathrm{~g}, 0.025 \mathrm{~mol})$ was slowly added to the solution and stirred for $10 \mathrm{~min}$. Finally, $20 \mathrm{~mL}$ of leaf extract (Murraya koenigii/Zingiber officinale) was added to the above mixture under constant stirring using magnetic stirrer for $10 \mathrm{~min}$. After complete dissolution of the mixture, the solution was boiled at $80^{\circ} \mathrm{C}$ for $10 \mathrm{~min}$. The immediate colour change after adding the leaf extract indicates the formation of $\mathrm{Ag} / \mathrm{CuO} \mathrm{NCs}$. The final product was washed with ethanol followed by deionized water and then it was allowed to dry under room temperature to get the $\mathrm{Ag} / \mathrm{CuO}$ nanocomposites.

The synthesized $\mathrm{Ag}$ and $\mathrm{CuO}$ nanoparticles are denoted as $\mathrm{S} 1$ and $\mathrm{C} 1$, respectively. $\mathrm{Ag} / \mathrm{CuO} \mathrm{NCs}$ synthesized through chemical method is denoted as $\mathrm{SC} 1$, while that obtained from Murraya koenigii and Zingiber officinale extracts are denoted as SC2 and SC3, respectively.

\subsection{Characterization}

FT IR spectra of synthesized nanomaterials were recorded at room temperature on Perkin-Elmer spectrophotometer in the range $4000-400 \mathrm{~cm}^{-1}$. Diffuse reflectance spectra were recorded using UV140404B spectrophotometer in the wavelength range 200-800 nm, and numerical data were plotted in the 'Origin 8 ' software. Photoluminescence spectra were recorded using FLUOROLOG-FL3-11fluorescence spectrometer. Powder X-ray diffraction data were collected between $10-90^{\circ}(2 \theta)$ at $0.5^{\circ} \mathrm{min}^{-1}$ from a highly stabilized and automated ZESSI X-ray generator (PW 1830) operated at $40 \mathrm{kV}$ and $20 \mathrm{~mA}$, with $\mathrm{Cu} \mathrm{K} \alpha$ radiation and $\lambda$ 
value is $1.5406 \AA$. SEM and EDX analysis were performed through JEOL 6500F instrument. TEM measurements were performed on a JEOL model 1200EX operated at an accelerating voltage of $120 \mathrm{kV}$.

\subsection{Phytochemical studies}

The aqueous Murraya koenigii and Zingiber officinale were subjected to qualitative and quantitative analysis for the identification of their active phytoconstituents [18-20]. The detailed procedures are reported in supplementary material (S1 and S2).

\subsection{Antidiabetic activity}

The in vitro antidiabetic activities against $\alpha$-amylase, $\alpha$-glucosidase and glucose-6phosphatase enzymes, glucose uptake activity were evaluated according to the reported procedures with some modification [21-23].

\subsection{1 $\alpha$-Amylase inhibitory activity}

$\alpha$-Amylase (0.05 g of $\alpha$-amylase in $100 \mathrm{~mL}$ of ice-cold distilled water) was premixed with the synthesized nanomaterials at different concentrations $(100-1.52 \mu \mathrm{g} / \mathrm{mL})$ and sonicated at room temperature for $30 \mathrm{~min}$. Starch as a substrate was added as a $0.5 \%$ starch solution in phosphate buffer to start the reaction. The assay mixture was incubated at $37{ }^{\circ} \mathrm{C}$ for $15 \mathrm{~min}$ and terminated by adding $2 \mathrm{~mL}$ of DNS reagent (1\% 3,5-dinitrosalicyclic acid and $12 \%$ sodium potassium tartrate in $0.4 \mathrm{M} \mathrm{NaOH})$. The reaction combination was then heated for $15 \mathrm{~min}$ at $100{ }^{\circ} \mathrm{C}$ in a boiling water. The $\alpha$-amylase inhibitiory activity was calculated as percentage inhibition using the following formula;

$$
\mathrm{I}_{\alpha \text {-Amylase }}(\%)=\frac{\mathrm{A} 540 \text { control }- \text { A540 sample }}{\text { A540 control }} \times 100
$$

where $\mathrm{A}_{540}$ control $=$ absorbance without nanomaterials, and $\mathrm{A}_{540 \text { sample }}=$ absorbance with nanomaterials. 


\subsection{2 $\alpha$-Glucosidase inhibitory activity}

$\alpha$-Glucosidase (0.05 g of $\alpha$-glucosidase in $100 \mathrm{~mL}$ of ice-cold distilled water) was pre-mixed with the synthesized nanomaterials at different concentration $(100-1.52 \mu \mathrm{g} / \mathrm{mL})$ and sonicated at room temperature for $30 \mathrm{~min}$. In order to start the reaction, $p$-nitrophenyl- $\alpha$ D-glucopyranoside $(3 \mathrm{mM})$ as a substrate in potassium phosphate buffer was added to the mixture. The reaction was incubated at $37{ }^{\circ} \mathrm{C}$ for $20 \mathrm{~min}$ and terminated by the addition of $\mathrm{Na}_{2} \mathrm{CO}_{3}(2 \mathrm{~mL}, 0.1 \mathrm{M})$. A tube containing $\alpha$-glucosidase without nanomaterials served as the control with $100 \%$ enzyme activity. $\alpha$-Glucosidase inhibitory activity was determined by measuring the release of $p$-nitrophenyl- $\alpha$-D-glucopyranoside as percentage inhibition using the following formula;

$$
\mathrm{I}_{\alpha-\text { Glucosidase }}(\%)=\frac{\mathrm{A} 405 \text { control }-\mathrm{A} 405 \text { sample }}{\mathrm{A} 405 \text { control }} \times 100
$$

where $\mathrm{A}_{405}$ control = absorbance without nanomaterials, and $\mathrm{A}_{405}$ sample $=$ absorbance with nanomaterials.

\subsubsection{Glucose-6-phosphatase inhibition activity}

The glucose-6-phosphatase activity was carried out using glucose-6-phosphatase from a rabbit liver (Sigma, G5758), and was determined by measuring the release of glucose-6phosphate at $660 \mathrm{~nm}$. Inhibition rates were calculated by using the following formula;

$$
\text { (\%) } \text { Inhibition }=\frac{\mathrm{A}_{\text {control }}-\mathrm{A}_{\text {sample }}}{\mathrm{A}_{\text {control }}} \times 100
$$

$\mathrm{IC}_{50}$ values were determined from dose-response curve of percentage inhibition versus nanomaterials concentration and compared with the $\mathrm{IC}_{50}$ value of the synthetic inhibitor of glucose-6-phosphatase (metformin), under similar conditions. 


\subsection{Glucose uptake determination}

The 3T3-L1 preadipocyte cells were cultured and plated in 24-well plate, and incubated for $24 \mathrm{~h}$ in DMEM growth medium containing glucose $(5 \mathrm{mM})$. Initially ( $1^{\text {st }}$ day), the growth medium was replaced by DMEM supplemented with $10 \%$ fetal calf serum (FCS), $10 \mu \mathrm{g} / \mathrm{mL}$ insulin, dexamethasone (DEX; $10^{-8} \mathrm{M}$ ) and 3-isobutyl-1-methylxanthine (IBMX; $0.1 \mathrm{mM})$. After $70 \mathrm{~h}$ ( $4^{\text {th }}$ day), this medium was replaced with growth medium. After $48 \mathrm{~h}$ incubation $\left(6^{\text {th }}\right.$ day), the cells were analyzed by removing $10 \mu \mathrm{L}$ of the media and placing in the 96 well plates to which GOD-POD reagent $(200 \mu \mathrm{L})$ was added and incubated for 15 min at $37^{\circ} \mathrm{C}$. The amount of glucose content $(\mathrm{mg} / \mathrm{dL})$ in each well was determined by using the following formula;

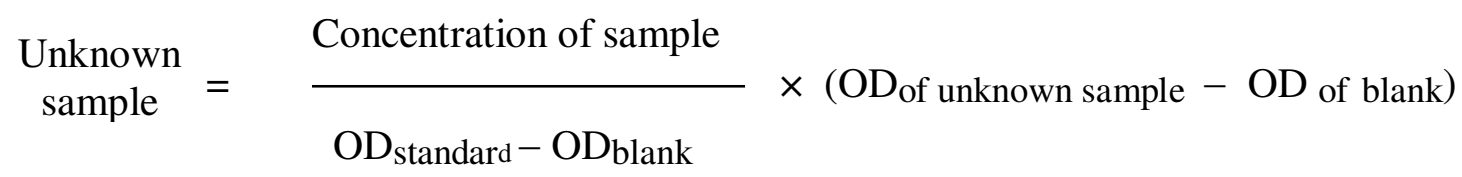

Finally, the glucose uptake over control was calculated as the difference between initial and final glucose content in the incubated medium.

\section{Results and discussion}

$\mathrm{Ag} / \mathrm{CuO}$ nanocomposites ( $\mathrm{NCs}$ ) were synthesized by green route using aqueous extracts of Murraya koenigii and Zingiber officinale. The use of these extracts leads to the reduction of metal ion to zero valent metal nanoparticles by avoiding the usage of common reducing agents such as sodium borohydride. In order to carry out comparison study, we have also synthesized the same nanocomposite by chemical methodology. The use of optimum plant extracts, which contain phytoconstituents of therapeutic values for the synthesis of NCs have induced us to investigate the in vitro antidiabetic activities of the synthesized NCs. 


\subsection{Phytochemical screening of green extracts}

The biomolecules present in plant extracts are safe and owns remedial merits as compared to the artificial drugs. Interestingly, Murraya koenigii and Zingiber officinale possesses a wealthy phytochemistry with reputable medicinal uses in traditional medicine, which originates from Rutaceae and Zingiberaceae families, respectively. Zingiber officinale has been used widely in Chinese, Indian and Unani medicines because of its potential therapeutic activity [24-26]. The green extracts contain several biomolecules such as amino acids, proteins, carbohydrates, flavonoids, glycosides, phenolic compounds, saponins and tannins (Table S1). Gums and mucilages, and terpenoids are missing in both the extracts. Rest of the compounds including alkaloids and phytosterols are available only in Zingiber officinale extract. In this regard, we have also quantitatively determined the essential phytoconstituents present in both the extracts (Table S2). The biomolecules such as falvonoids and phenolic compounds may have the potential to bind metal ions and cause reduction to metal nanoparticles. The results support the role of flavonoids and phenolic compounds in the bioreduction. 


\subsection{Structural, optical and morphological characterization}

\subsubsection{FT IR analysis}

The FT IR spectra revealed the bioreduction role of major phytoconstituents present in the extracts and the effective incorporation of green exracts on the synthesized nanomaterials (Fig. 1). The band observed at $\sim 3450 \mathrm{~cm}^{-1}$ for all the synthesized NCs attributed to the stretching vibration of the moisture content and the band in the region 1650$1670 \mathrm{~cm}^{-1}$ corresponding to the $\mathrm{H}-\mathrm{O}-\mathrm{H}$ bending vibration of water molecule [27]. The photosynthesized NCs exhibit absorption band at $1038 \mathrm{~cm}^{-1}$ ascribed to $\mathrm{C}-\mathrm{O}$ stretching characteristics of polysaccharides. The bands at $\sim 2920$ and $\sim 2860 \mathrm{~cm}^{-1}$ are due to $\mathrm{C}-\mathrm{H}$ vibration modes and that observed at $\sim 1720$ and $\sim 1610 \mathrm{~cm}^{-1}$ attributed to stretching vibration of carboxyl group $(\mathrm{C}=\mathrm{O})$ of the extracts [28]. The band observed at $\sim 1100 \mathrm{~cm}^{-1}$ is due to $\mathrm{C}-$ $\mathrm{C}$ vibration (skeletal). The characteristic absorption peaks of $\mathrm{Cu}-\mathrm{O}$ vibrations are indexed around $530 \mathrm{~cm}^{-1}$ [29-31]. The FT IR spectra of $\mathrm{Ag} / \mathrm{CuO}$ NCs show all the characteristics vibrations of functional groups of silver and $\mathrm{CuO}$ NPs. The characteristic peaks of functional groups of the extracts indicate the role of secondary metabolites in the synthesis of nanocomposites. 
(A)

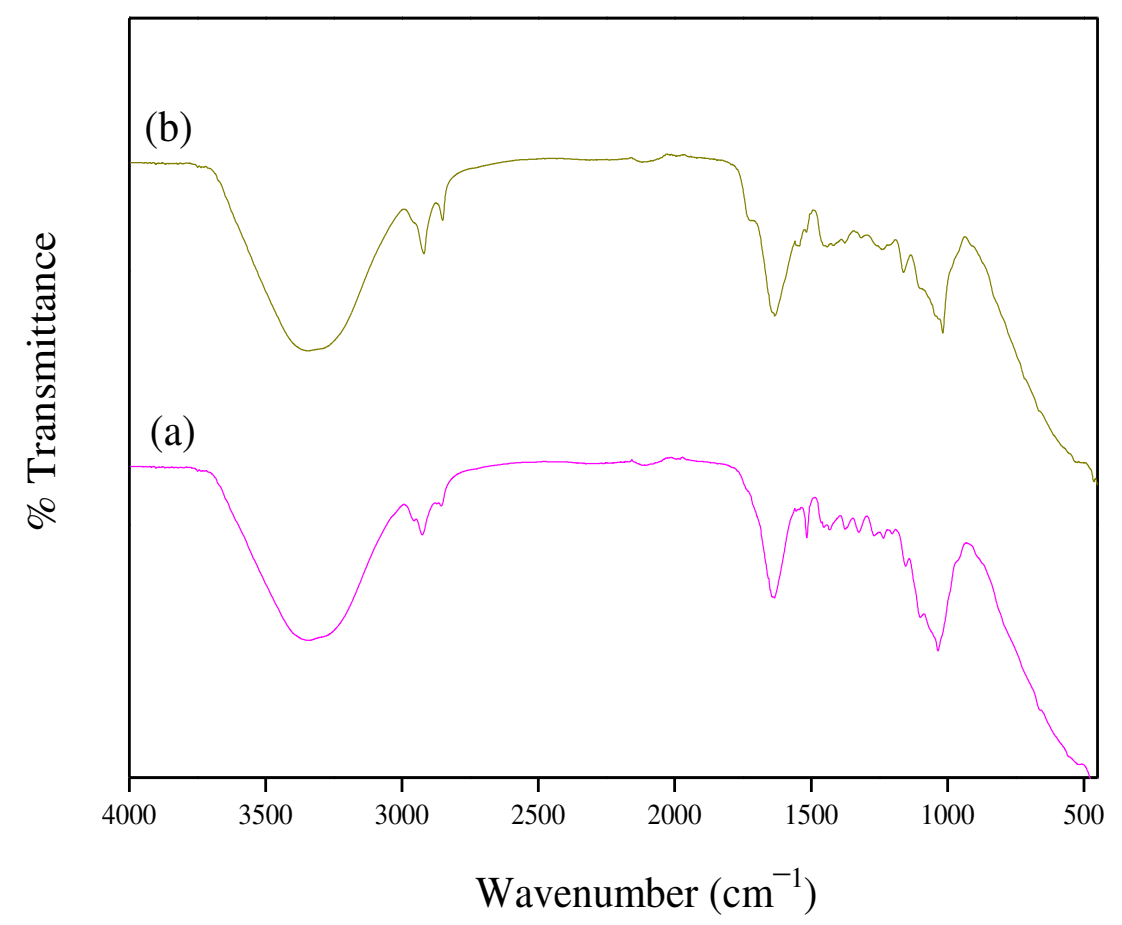

(B)

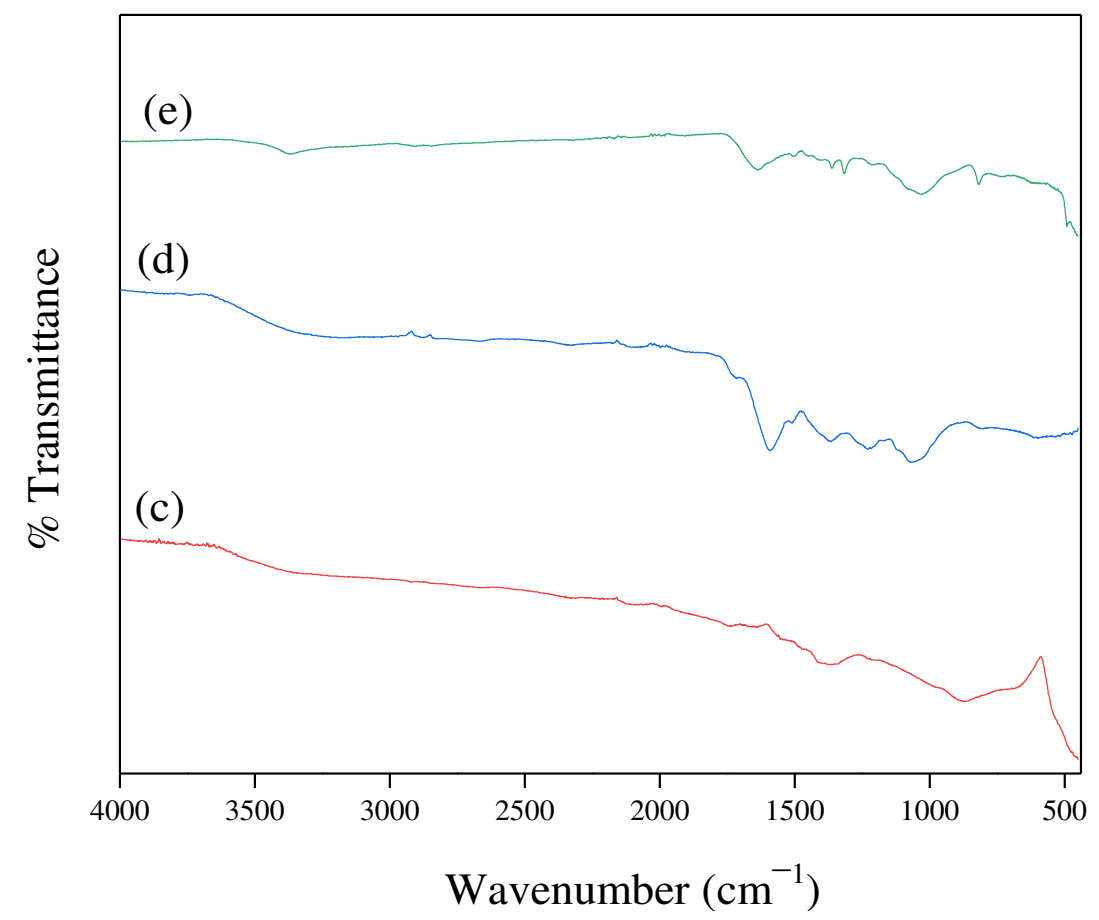

Fig. 1. FT IR spectra of green extracts (A): Murraya koenigii extract (a) and Zingiber officinale extract (b), and nanomaterials (B): C1 (c), SC2 (d) and SC3 (e). 


\subsubsection{UV-Vis DRS spectral studies}

The UV-Vis DRS spectroscopy is used to understand the formation of $\mathrm{Ag} / \mathrm{CuO} \mathrm{NCs}$ (Fig. 2). The optical characteristics of the metal nanoparticles in composite are considerably differing from individual metal nanoparticles. The maximum absorption at $\sim 290$ and $\sim 470$ $\mathrm{nm}$ for the $\mathrm{Ag} / \mathrm{ZnO} \mathrm{NCs}$ corresponds to $\mathrm{CuO}$ and $\mathrm{AgNPs}$, respectively. The successful deposition of AgNPs into $\mathrm{CuO}$ NPs were confirmed by the stronger absorption surface plasmon resonance peaks observed for nanocomposites compared to the original nanomaterials $[2,28]$. The diffuse reflectance spectroscopy is used to analyse the width of the energy gap using the Kubelka-Munk (K-M) model [32]. A graph plotted between $[F(\mathrm{R}) h v]^{2}$ and $\mathrm{h} v$, in which the intercept value is the bandgap energy, and the bandgap values is found to be in the range between 1.61 and $1.77 \mathrm{eV}$ for $\mathrm{Ag} / \mathrm{CuO} \mathrm{NCs}$, and $1.39 \mathrm{eV}$ for $\mathrm{CuO}$ nanoparticles, which authenticate the deposition of $\mathrm{Ag}$ into $\mathrm{CuO}$ nanoparticles (Fig. 3 and Table 1). The bandgaps of $\mathrm{Ag} / \mathrm{CuO} \mathrm{NCs}$ are higher than that of $\mathrm{CuO}$ NPs. The larger bandgaps are generally linked with smaller size that leads to exhibit higher level of biological activity [33]. 


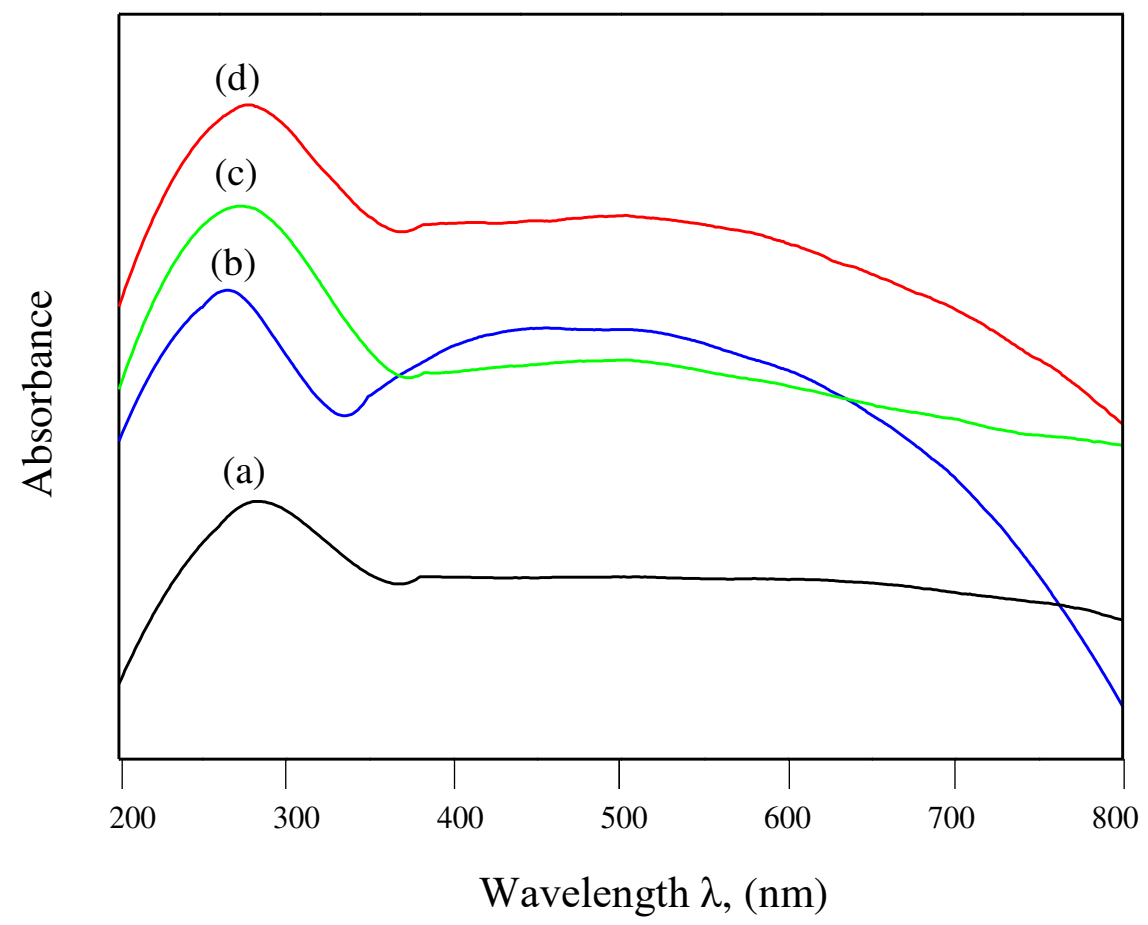

Fig. 2 UV-Vis DRS spectra of C1 (a), SC1 (b), SC2 (c) and SC3 (d).
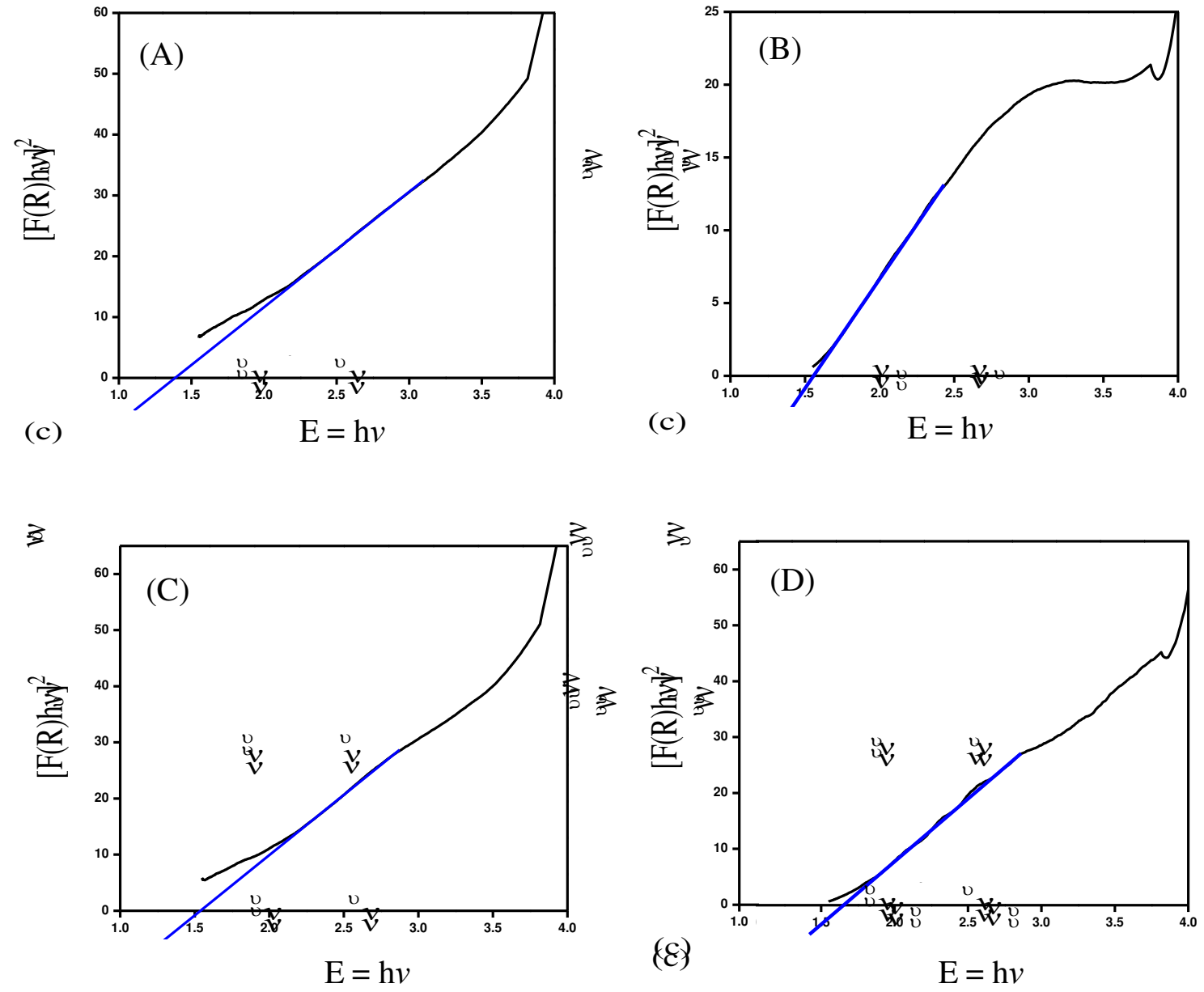

Fig. 3 Estimated bandgap of C1 (a), SC1 (b), SC2 (c) and SC3 (d). 


\subsubsection{Powder XRD analysis}

The XRD analysis was performed to ascertain the crystalline nature and phase purity of the synthesized nanomaterials (Fig. 4). The diffractogram of CuO NPs show diffraction peaks at $2 \theta$ values $32.3,35.6,38.2,48.7,53.6,58.2,61.5,66.2,68.2$ and $72.3^{\circ}$, which can be indexed to (110), (-111), (111), (-202), (020), (202), (-113), (-311), (220), and (311) planes with monoclinic $\mathrm{CuO}$ phase (JCPDS card No. 05-0661). There are two mixed sets of diffraction peaks appeared for $\mathrm{Ag} / \mathrm{CuO}$ NCs. The diffraction peaks at $2 \theta$ values $38.1,44.3$ and $64.4^{0}$ can be indexed to (111), (200) and (220) planes assigned to crystalline facecentered cubic Ag structure (JCPDS card No. 65-2841) [34, 35]. The XRD patterns confirmed the presence of both $\mathrm{CuO}$ nanocrystals and $\mathrm{Ag}$ nanoparticles in the synthesized $\mathrm{Ag} / \mathrm{CuO} \mathrm{NCs}$ with no other peaks due to any impurities. The crystalline sizes of the synthesized nanomaterials are calculated by using the Debye-Scherrer's formula;

$$
\mathrm{D}=\frac{K \lambda}{\beta \cos \theta}
$$

where $\mathrm{D}$ is the average crystallite size, $K$ is a grain sharp factor $(0.94), \lambda$ is the incident $\mathrm{X}$-ray wavelength (1.5418 $\AA$ ), $\beta$ is the full width at half maximum (FWHM) of the diffraction peak, and $\theta$ is the Bragg's angle of peak. The average crystalline size of the synthesized nanomaterials is shown in Table 1. 


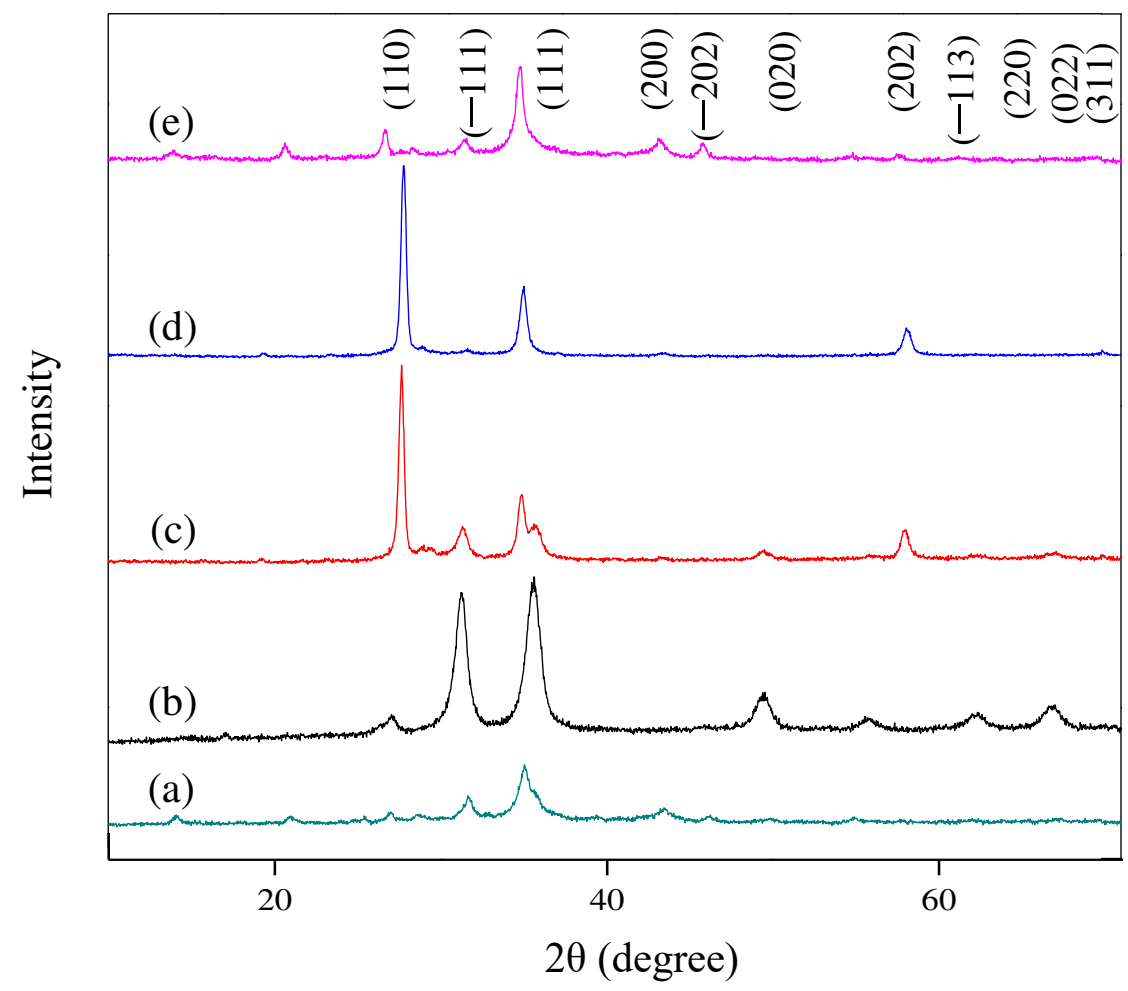

Fig. 4. X-Ray diffraction patterns of S1 (a), $\mathrm{C} 1$ (b), SC1 (c), SC2 (d) and SC3 (e).

Table 1 Average crystallite size and bandgap values of nanomaterials determined by XRD, TEM and UV-Vis DRS techniques.

\begin{tabular}{cccc}
\hline Nanomaterials & $\begin{array}{c}\text { Crystalline size } \\
(\mathrm{nm})(\mathrm{XRD})\end{array}$ & $\begin{array}{c}\text { Particle size } \\
(\mathrm{nm})(\mathrm{TEM})\end{array}$ & $\begin{array}{c}\text { Bandgap (eV) } \\
\text { (UV-Vis DRS) }\end{array}$ \\
\hline $\mathrm{S} 1$ & 18.54 & 18.12 & - \\
\hline $\mathrm{C} 1$ & 19.71 & 19.64 & 1.38 \\
\hline $\mathrm{SC} 1$ & 21.59 & 21.78 & 1.62 \\
\hline $\mathrm{SC} 2$ & 22.10 & 21.83 & 1.61 \\
\hline $\mathrm{SC} 3$ & 22.43 & 20.14 & 1.63 \\
\hline
\end{tabular}




\subsubsection{SEM and EDX analysis}

The SEM images of $\mathrm{CuO}$ and $\mathrm{Ag} / \mathrm{CuO}$ NCs revealed the spherical shapes of the synthesized nanomaterials $[31,36]$. It could be seen that the AgNPs are deposited on the surface of the $\mathrm{CuO}$ nanostructures, and having roughened surfaces. The elemental composition of the nanocomposites was demonstrated by EDX analysis, which shows the presence of $\mathrm{Ag}, \mathrm{Cu}$ and $\mathrm{O}$ elements in the synthesized nanocomposites. The presence of strong $\mathrm{Ag}$ signal authenticate the deposition of $\mathrm{Ag}$ into $\mathrm{CuO}$. In addition to the strong signals due to $\mathrm{Ag}$ and $\mathrm{Cu}$, the $\mathrm{NCs}$ synthesized using green extracts also exhibit weak signals from $\mathrm{C}$, $\mathrm{S}, \mathrm{Cl}, \mathrm{O}$ and $\mathrm{P}$ due to the phytoconstituents of the extracts [37]. The nanomaterials synthesized through chemical method shows no other extra signal, which confirm the purity of the samples (Figs. $5 \& \mathbf{6}$ ).

\subsubsection{TEM analysis}

The TEM images of the synthesized $\mathrm{Ag} / \mathrm{CuO} \mathrm{NCs}$ exhibit the uniform dispersion by contrast and colour differences with an average size between 18 and $22 \mathrm{~nm}$ (Fig. 7). The size of the nanomaterials calculated from XRD analysis is closely matched with TEM results. The AgNPs appeared to be a black in colour and $\mathrm{CuO}$ was light due to high mass thickness of $\mathrm{Ag}$ $[36,37]$. 

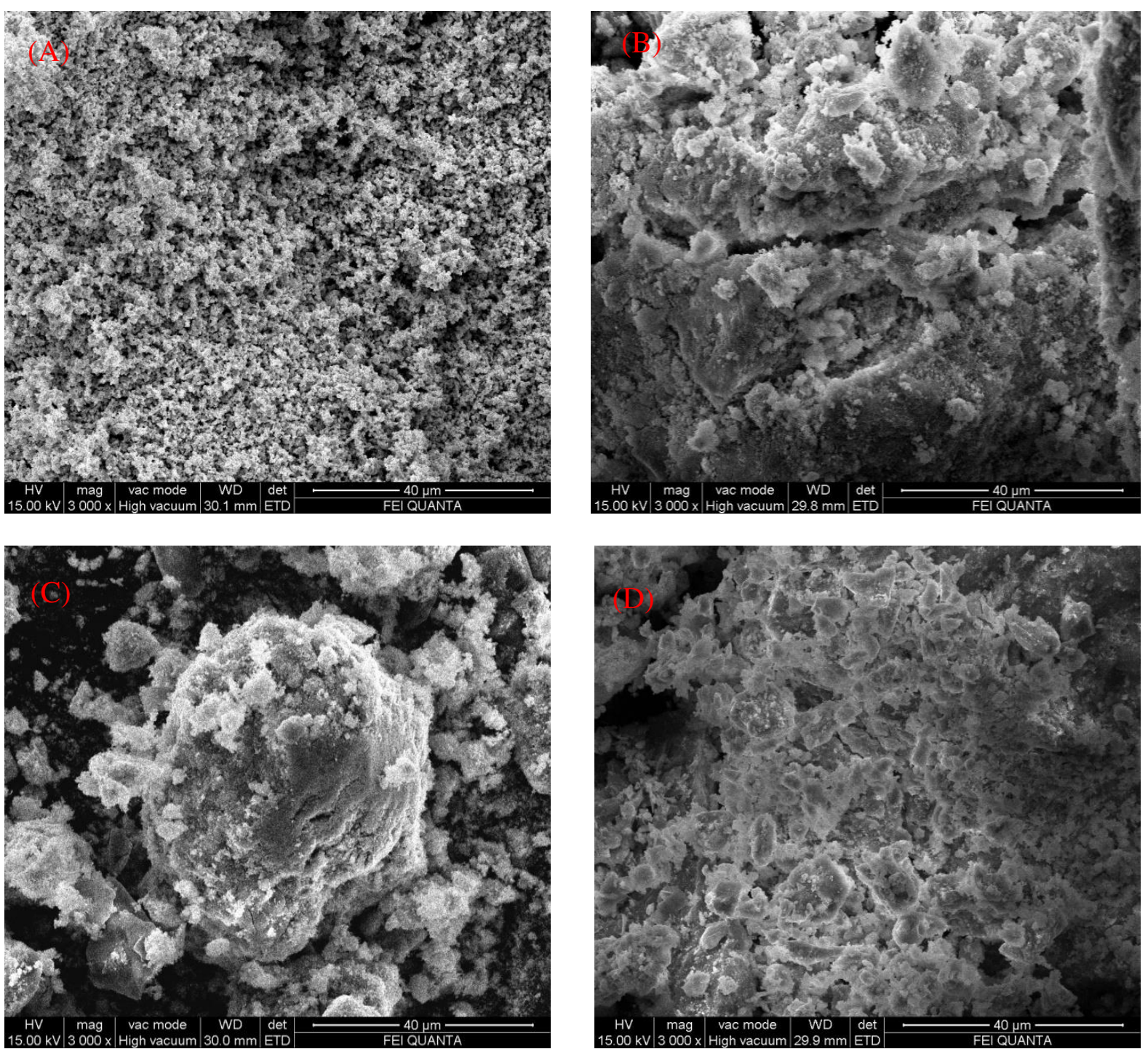

Fig. 5 SEM images of nanomaterials: S1 (a), C1 (b), SC1 (c) and SC2 (d). 

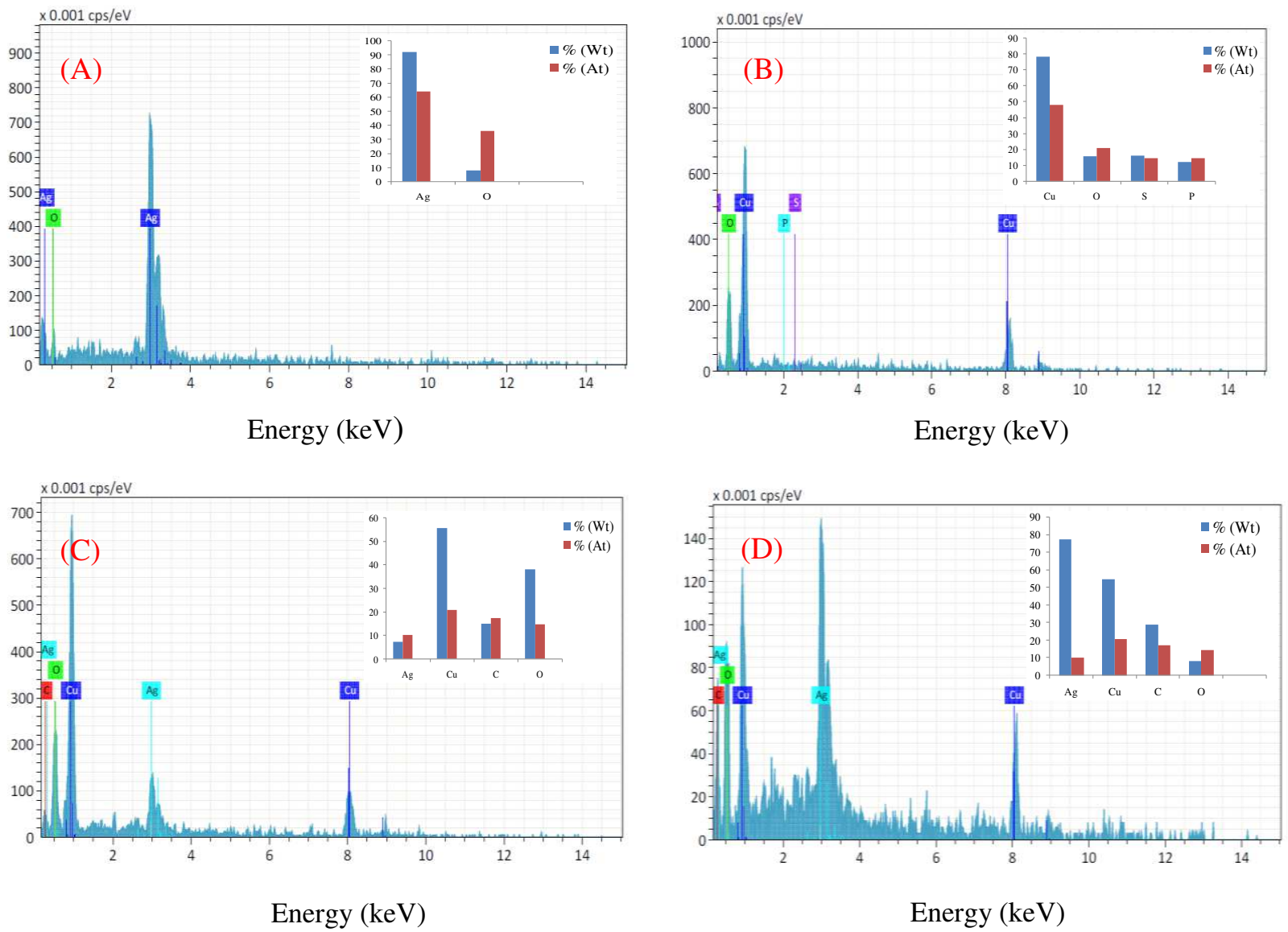

Fig. 6 Energy dispersive spectra of nanomaterials: S1 (a), C1 (b), SC1 (c) and SC2 (d).

\subsection{Antidiabetic activity}

Diabetes is a tricky disease that refers to a metabolic disorder distinguished by higher range of blood glucose level, and classified into Type 1, Type 2 and gestational type diabetes. The Type 2 diabetes received considerable attention as it influences a large proportion of populates worldwide by increasing the blood glucose level to insulin resistance in adipose tissue, muscle and liver [38]. The inhibition of carbohydrate enzymes prevent the increase of glucose level in blood. Sulfonylureas, biguanides, genistein, astilbin and hesperidin are generally recommended antidiabetic drugs for the purpose of controlling the blood glucose level $[39,40]$. The carbohydrate digesting enzymes such as $\alpha$-amylase and $\alpha$-glucosidase avoid the sudden raise of glucose level in blood. Acarbose, miglitol and voglibose are commonly utilized as standards in $\alpha$-amylase and $\alpha$-glucosidase inhibiton activity [41]. 

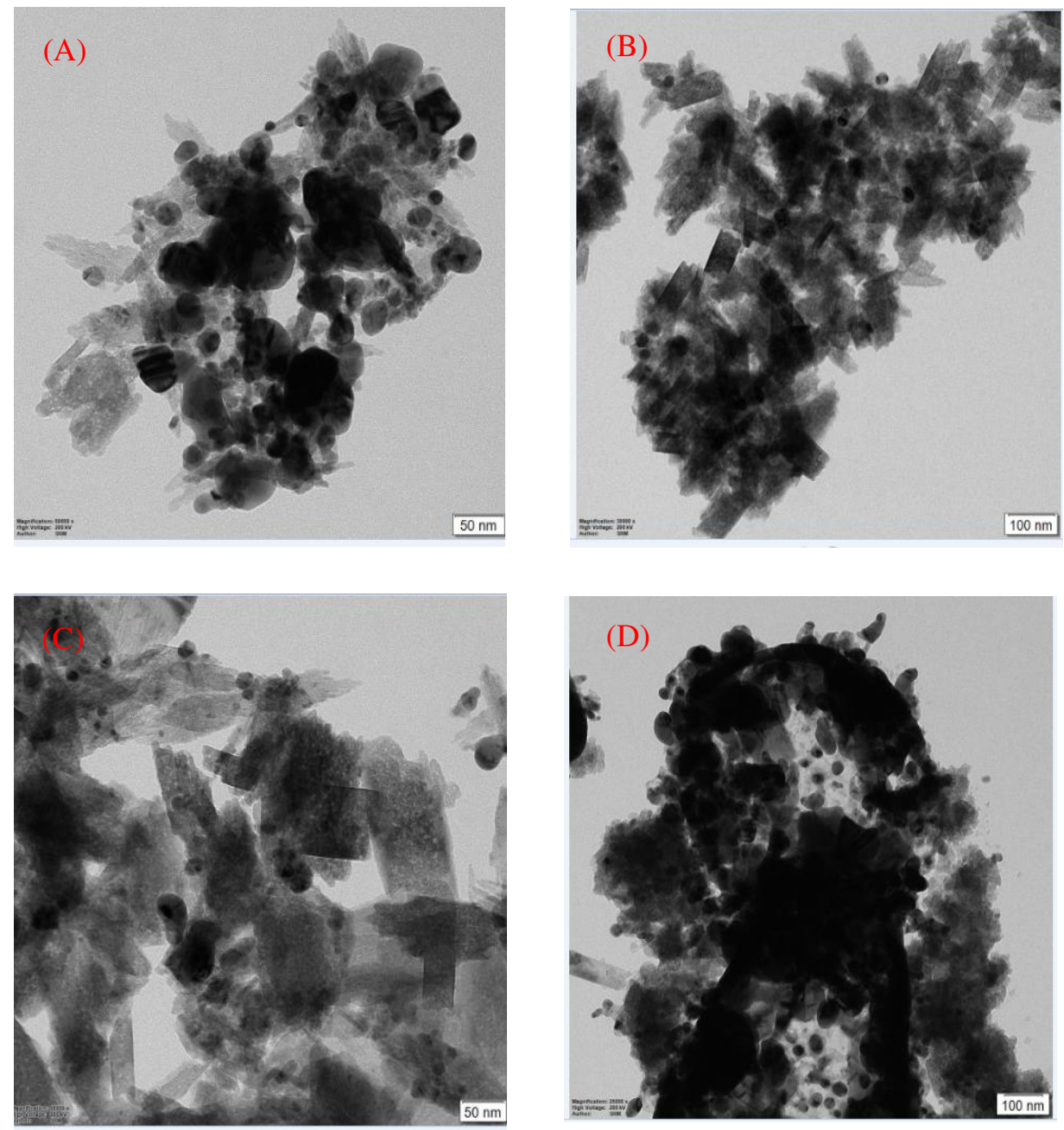

Fig. 7. TEM images of nanomaterials: C1 (a), SC1 (b), SC2 (c) and SC3 (d).

\subsection{1 $\alpha$-Amylase and $\alpha$-glucosidase inhibion activity}

The in vitro $\alpha$-amylase and $\alpha$-glucosidase inhibition activity of the synthesized nanomaterials were carried out with respect to the standard drug acarbose (Table 2 and Fig. 8). The inhibitory reports revealed that the nanomaterials synthesized utilizing green extracts exhibit higher antidiabetic activity than that synthesized by chemical method, and Ag and $\mathrm{CuO}$ nanoparticles. The $\mathrm{Ag} / \mathrm{CuO} \mathrm{NC}$ synthesized using Zingiber officinale extract (SC3) displayed higher $\alpha$-amylase and $\alpha$-glucosidase inhibition activity when compared to that synthesized using Murraya koenigii extract and other nanomaterials. The presence of higher content of phenolic $(137.41 \pm 3.161 \mathrm{mg} \mathrm{GAE} / \mathrm{g} \mathrm{dw})$ and flavonoid $(93.82 \pm 1.201 \mathrm{mg} \mathrm{QE} / \mathrm{g}$ $\mathrm{dw}$ ) compounds in Zingiber officinale extract when compared to Murraya koenigii (127.68 \pm 
$2.142 \mathrm{mg} \mathrm{GAE} / \mathrm{g} \mathrm{dw}$ and $61.27 \pm 2.124 \mathrm{mg} \mathrm{QE} / \mathrm{g} \mathrm{dw}$, respectively) may be the reason for the higher antidiabetic activity exhibited by SC3 compared to the rest of the nanomaterials. Based on the obtained results, the phytosynthesized $\mathrm{Ag} / \mathrm{CuO} \mathrm{NCs}$ could be suggested for further antidiabetic studies in order to explore the medicinal applications.

Table 2 Inhibitory effect of nanomaterials on $\alpha$-amylase and $\alpha$-glucosidase activity.

\begin{tabular}{ccc}
\hline \multirow{2}{*}{$\begin{array}{c}\text { Nanomaterials/ } \\
\text { Standard }\end{array}$} & $\alpha$-Amylase & $\alpha$-Glcosidase \\
\cline { 2 - 3 } S1 & $33.46 \pm 1.825$ & $13.74 \pm 1.236$ \\
\hline $\mathrm{C} 1$ & $38.91 \pm 1.741$ & $17.41 \pm 1.241$ \\
\hline $\mathrm{SC} 1$ & $36.38 \pm 1.297$ & $19.62 \pm 1.864$ \\
\hline $\mathrm{SC} 2$ & $24.32 \pm 1.448$ & $11.42 \pm 0.964$ \\
\hline $\mathrm{SC} 3$ & $22.37 \pm 1.268$ & $10.33 \pm 0.984$ \\
\hline Acarbose & $12.426 \pm 1.246$ & $4.281 \pm 0.164$ \\
\hline
\end{tabular}

Data are expressed as mean $\pm \mathrm{SEM} ; *$ Average of three independent determinations.

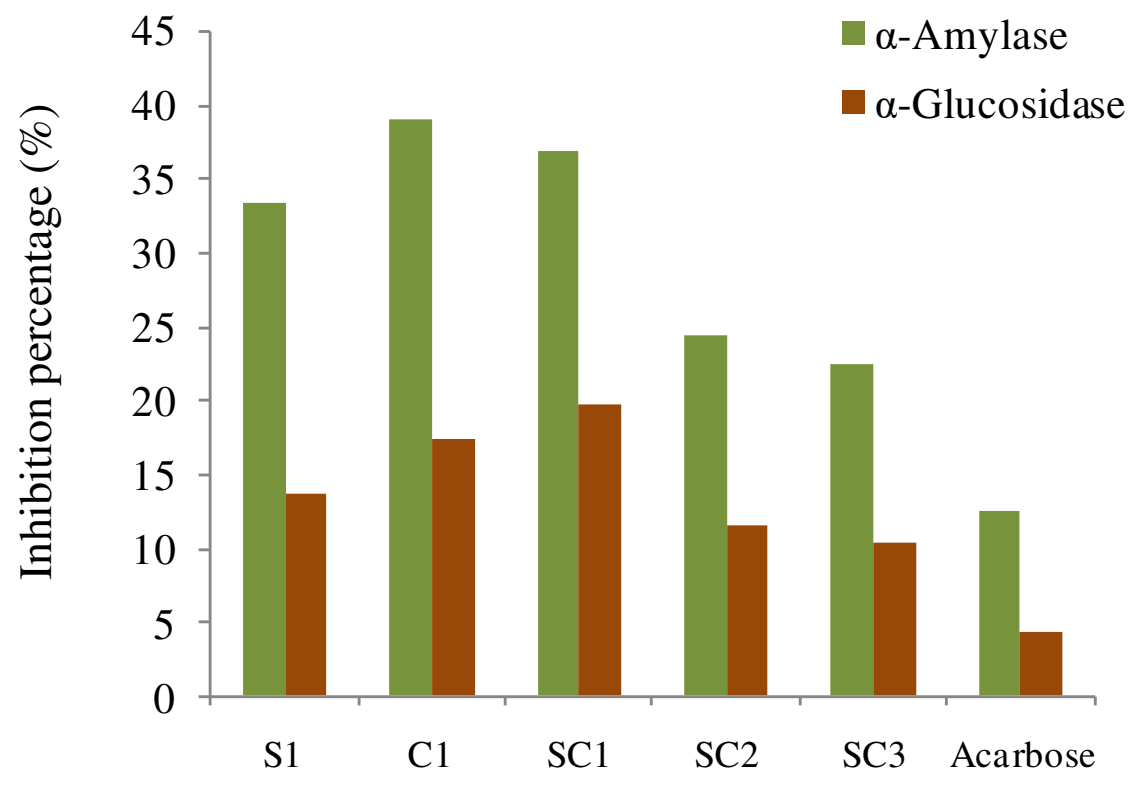

Fig. 8 Percentage of $\alpha$-amylase and $\alpha$-glucosidse inhibitory activity of nanomaterials. 


\subsubsection{Glucose-6-phosphatase inhibitory activity}

Glucose-6-phosphatase is an enzyme made up of proteins, phosphate group and glucose. Glucose exported from cell via glucose transporter membrane proteins. This catalysis is used in gluconeogenesis and plays a key role in the homeostatic regulation of blood glucose level [23]. Generally, glucose-6-phosphatase targets insulin action by inhibiting hyperglycaemia state and it prevent the production of glucose. In type II diabetes, liver becomes resistant to insulin and overexpression of glucose-6-phosphatase leads to uncontrolled gluconeogenesis [42, 43]. The inhibition activity of the synthesized nanomaterials was carried out against glucose-6-phosphatase with respect to the standard drug, metformin under identical conditions (Table 3 and Fig. 9). The obtained results revealed that $\mathrm{Ag}$ and $\mathrm{CuO} \mathrm{NPs}$, and the nanocomposite synthesized by chemical method showed weak activity when compared to the nanocomposites synthesized by green methods. The nanocomposite synthesized using Zingiber officinale extract (SC3) showed higher activity among the nanomaterials with respect to their $\mathrm{IC}_{50}$ values because of the rich amount of phytochemicals present in the green extract, which leads to reduce the glucose formation.

Table 3. Inhibitiory effect of nanomaterials on glucose-6-phosphatase enzyme.

\begin{tabular}{|c|c|}
\hline \multirow{2}{*}{$\begin{array}{c}\text { Nanomaterials/ } \\
\text { Standard }\end{array}$} & $\mathrm{IC}_{50}(\mu \mathrm{g} / \mathrm{mL})^{*}$ \\
\hline & Glucose-6-Phosphatase \\
\hline S1 & $68.53 \pm 3.258$ \\
\hline $\mathrm{C} 1$ & $65.47 \pm 4.202$ \\
\hline SC1 & $62.49 \pm 2.986$ \\
\hline $\mathrm{SC} 2$ & $49.02 \pm 2.613$ \\
\hline SC3 & $42.13 \pm 3.151$ \\
\hline Metformin & $28.61 \pm 1.823$ \\
\hline
\end{tabular}

Data are expressed as mean $\pm \mathrm{SEM}$; *Average of three independent determinations. 


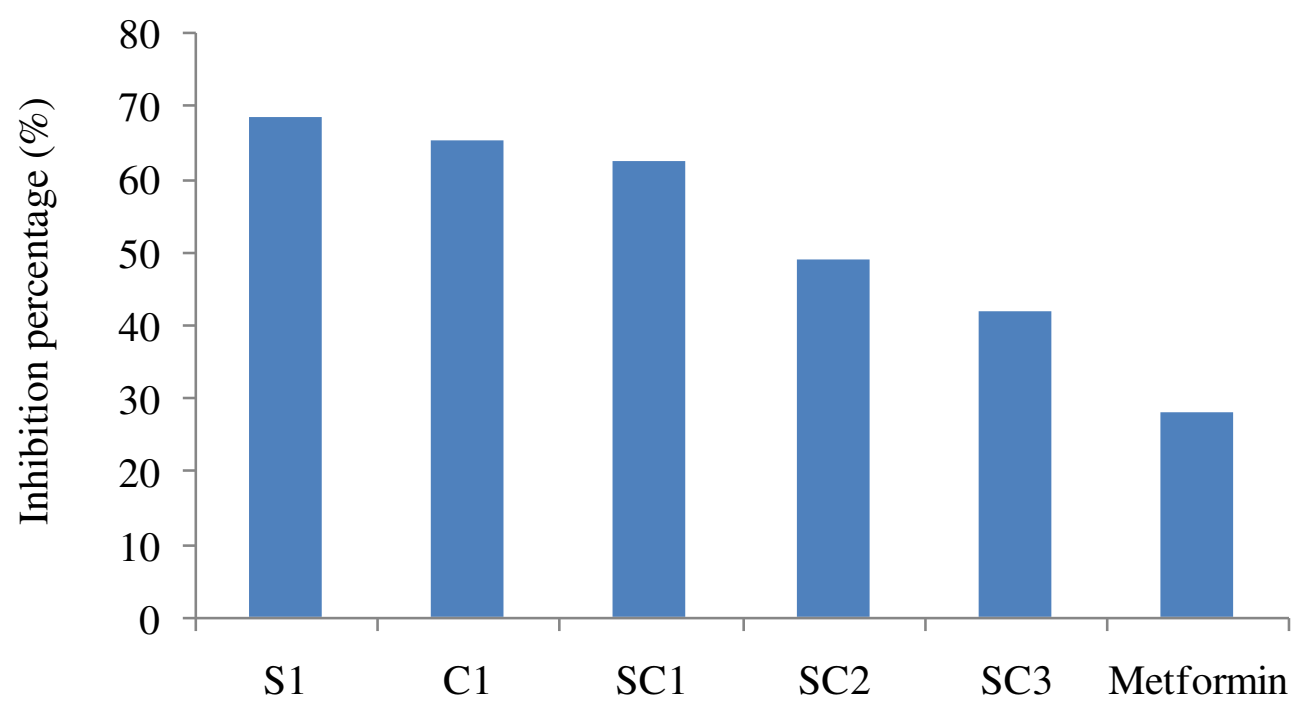

Fig. 9. Bar diagram showing the inhibition of glucose-6-phosphatase enzyme by nanomaterials.

\subsubsection{Glucose uptake assay}

Glucose uptake assay is a simple, non-radioactive assay, which helps in measuring the uptake of glucose inside the cells. The Type 2 diabetes is associated with lack of insulinstimulated glucose uptake, while high glucose uptake is a sign of high glucolytic rate associated with cancer. Glucose uptake assay was carried out against 3T3-L1 adipocyte cells at a concentration of $100 \mu \mathrm{g} / \mathrm{mL}$ in the presence of insulin and metaformin, and the synthesized nanomaterials, both separately and in combination to each other (Table 4 and Fig. 10). The results revealed that all the nanomaterials exhibit considerable activity against the 3T3-L1 cells. Addition of insulin and metformin to the nanomaterials further increased the uptake of glucose percentage. It could be noticed that the NCs synthesized using green extracts (SC2 and SC3) showed considerable glucose uptake when combined with insulin and metformin. Further, among the nanocomposites, the $\mathrm{Ag} / \mathrm{CuO}$ NCs synthesized using Zingiber officinale extract (SC3) shows higher activity compared to the other nanomaterials. 
Table 4 Effect of insulin, metformin and nanomaterials on glucose uptake $\%$.

\begin{tabular}{ll}
\hline Test/Standard & Glucose uptake $(\%)$ \\
\hline Insulin & $98.41 \pm 4.326$ \\
\hline Metformin & $95.22 \pm 3.249$ \\
\hline Insulin + Metformin & $99.36 \pm 2.947$ \\
\hline $\mathrm{S} 1$ & $76.42 \pm 2.265$ \\
\hline $\mathrm{S} 1+$ Insulin & $82.43 \pm 2.861$ \\
\hline $\mathrm{S} 1+$ Insulin + Metformin & $91.47 \pm 3.752$ \\
\hline $\mathrm{C} 1$ & $71.94 \pm 2.287$ \\
\hline $\mathrm{C} 1+$ Insulin & $85.38 \pm 3.912$ \\
\hline $\mathrm{C} 1+$ Insulin + Metformin & $90.38 \pm 3.123$ \\
\hline $\mathrm{SC} 1$ & $82.32 \pm 2.642$ \\
\hline $\mathrm{SC} 1+$ Insulin & $91.47 \pm 2.281$ \\
\hline $\mathrm{SC} 1+$ Insulin + Metformin & $96.86 \pm 3.112$ \\
\hline $\mathrm{SC} 2$ & $92.37 \pm 4.381$ \\
\hline $\mathrm{SC} 2+$ Insulin & $96.78 \pm 3.227$ \\
\hline $\mathrm{SC} 3 \mathrm{SC} 3+$ Insulin + Metformin & $92.64 \pm 3.123$ \\
\hline
\end{tabular}

Data are expressed as mean $\pm \mathrm{SEM}$; *Average of three independent determinations. 


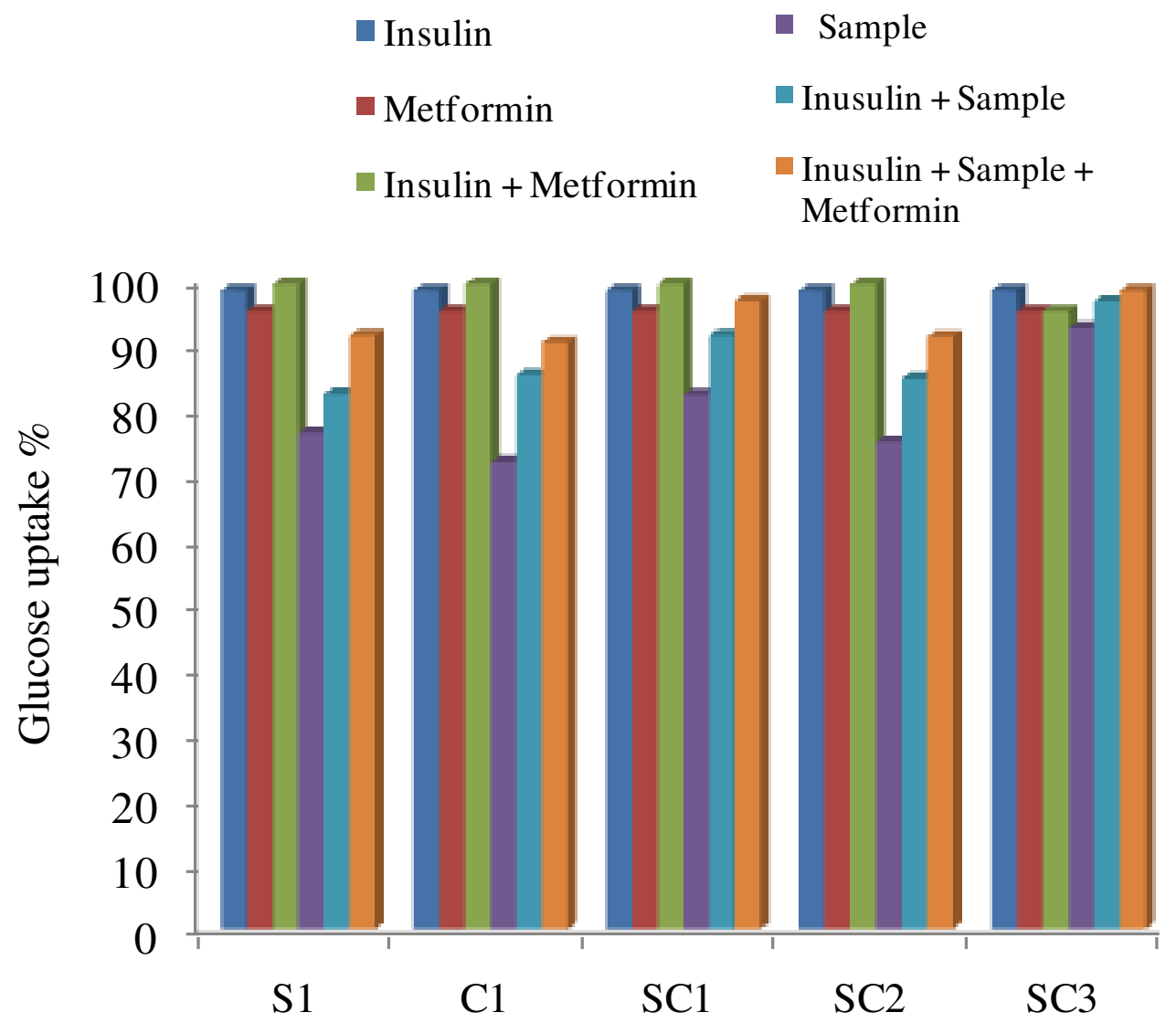

Fig. 10. Effect of insulin, metformin and nanomaterials on 3T3-L1 adipocyte cells showing glucose uptake \%. 


\section{Conclusion}

In this chapter, we have reported eco-friendly and simple biosynthesis of $\mathrm{Ag} / \mathrm{CuO}$ NCs using Murraya koiengii and Zingiber officinale extracts. The biomolecules present in the green extracts assist the reduction process and contribute interesting methodology towards the fabrication of nanomaterials. The functional groups present in the green synthesized NCs were confirmed by FT IR spectroscopy. The UV-Vis DRS spectra revealed the formation of nanocomposites by exhibiting two absorption bands at $\sim 290 \mathrm{~nm}$ and $\sim 460 \mathrm{~nm}$ corresponding to $\mathrm{CuO}$ and $\mathrm{AgNPs}$, respectively. The morphological analysis confirmed the spherical shape of the synthesized nanomaterials, whereas the elemental composition authenticated the presence of $\mathrm{Ag}, \mathrm{O}, \mathrm{S}, \mathrm{C}, \mathrm{P}$ and $\mathrm{Cu}$ elements in the phytosynthesized nanomaterials. The TEM results confirmed the formation of nanocomposites with an average particle size of 18-22 $\mathrm{nm}$. The nanocomposites synthesized using Zingiber officinale extract showed higher in vitro inhibition activity against $\alpha$-amylase, $\alpha$-glucosidase and glucose-6-phosphatase enzymes. Further, the glucose uptake assay in 3T3-L1 adipocyte cells revealed the higher uptake of glucose for the nanocomposite synthesized using Zingiber officinale extract on addition of insulin and metformin. The presence of higher amount of phytochemicals such as phenolic $(137.41 \pm 3.161 \mathrm{mg} \mathrm{GAE} / \mathrm{g} \mathrm{dw})$ and flavonoid $(93.82 \pm 1.201 \mathrm{mg} \mathrm{QE} / \mathrm{g} \mathrm{dw})$ compounds in the Zingiber officinale extract may be the prime reason for the higher antidiabetic activity exhibited by the $\mathrm{Ag} / \mathrm{ZnO} \mathrm{NC}$ synthesized using Zingiber officinale extract (SC3). The $\mathrm{Ag} / \mathrm{CuO} \mathrm{NCs}$ synthesized through green extracts may be utilized as therapeutic agents in future.

\section{Compliance with Ethical Standards}

Conflict of interest The authors declare that they have no competing interest. 


\section{References}

1. B. Ajitha, Y.A. Reddy, P.S. Reddy, Spectrochim. Acta A 128, 257 (2014)

2. E.E. Elemike, D.C. Onwudiwe, D.F. Ogeleka, J.I. Mbonu, J. Inorg. Organomet. Polym. Mater. 29, 1798 (2019)

3. G. Manjari, S. Saran, S.P. Devipriya, A.V. Rao, Catal. Lett. 148, 2561 (2018)

4. A. Goswam, A.K. Rathi, C. Aparicio, O. Tomanec, M. Petr, R. Pocklanova, M.B. Gawande, R.S. Varma, R. Zboril, ACS Appl. Mater. Interfaces 9, 2815 (2017)

5. Q. Sheng, Y. Shen, J. Zhang, J. Zheng, Anal. Methods 9, 163 (2017)

6. J.B. Reitz, E.I. Solomon, J. Am. Chem. Soc. 120, 114 (1998)

7. P. Poizot, S. Laruelle, S. Grugeon, L. Dupont, J.M. Taracon, Nature 407, 496 (2000)

8. X. Gao, J. Bao, G. Pan, H. Zhu, P. Huang, W. Wu, J. Phys. Chem. B 108, 55 (2004)

9. W.H. Antink, Y. Choi, K. Seong, Y. Piao, Sens. Actuators B Chem. 255, 1995 (2018)

10. D. Das, B.C. Nath, P. Phukon, S.K. Dolui, Colloids Surf. B 101, 430 (2013)

11. D. Philip, C. Unni, S.A. Aromal, V.K. Vidhu. Spectrochim. Acta A 78, 899 (2011)

12. A. Khurana, M.S. Sikha, K. Ramesh, P. Venkatesh, C. Godugu, Phytother. Res. 33, 1510 (2019)

13. I. Stoilova, A. Krastanov, A. Stoyanova, P. Denev, S. Gargova, Food Chem. 102, 764 (2007)

14. D. Rehana, D. Mahendiran, R.S. Kumar, A.K. Rahiman, Biomed. Pharmacother. 89, 1067 (2017)

15. D.A. Selvan, D. Mahendiran, R.S. Kumar, A.K. Rahiman, J. Photochem. Photobio. B 180, $243(2018)$

16. R. Sivraj, P.K.S.M. Rahiman, P. Rajiv, H.A. Salam, R. Venckatesh, Spectrochim. Acta A 133, 746 (2014)

17. M.S. Jadhav, S. Kulkarni, P. Raikar, D.A. Barretto, S.K. Vootla, U.S. Raikar New J. Chem. 42, 204 (2018)

18. J.B. Harborne, Methods of plant analysis. In phytochemical methods, Chapman and Hall, London (1973). 
19. J.N. Eloff, J. Ethnopharmacol. 60, 1 (1998)

20. J.B. Harborne, Phytochemical methods: A guide to modern techniques of plant analysis, Chapman and Hall, London (1984).

21. V.G. Kumar, S.D. Gokavarapu, A. Rajeswari, T.S. Dhas, V. Karthick, Z. Kapadia, T. Shrestha, I.A. Barathy, A. Roy, S, Sinha, Colloids Surf. B 87, 159 (2011)

22. D. Rehana, D. Mahendiran, R.S. Kumar, A.K. Rahiman, Bioprocess Biosyst. Eng. 89, 1067 (2017)

23. L. Yang, X.F. Li, L. Gao, Y.O. Zhang, G.P. Cai, Phytother. Res. 26, 438 (2012)

24. B.H. Ali, G. Blunden, M.O. Tanira, N. Nemmar, Food Chem. Toxicol. 46, 409 (2008)

25. G. Singh, I.P. Kapoor, P. Singh, C.S. Heluani, M.P. Lampasona, C.A. Catalan, Food Chem. Toxicol. 46, 3295 (2008)

26. S. Azizi, R. Mohamad, R.A. Rahim, A.B. Moghaddam, M. Moniri, A. Ariff, W.Z. Saad, F. Namvab, Appl. Surf. Sci. 384, 517 (2016)

27. P.A. Arciniegas-Grijalba, M.C. Patiño-Portela, L.P. Mosquera-Sánchez, J.A. Guerrero-Vargas, J.E. Rodríguez-Páez, Appl. Nanosci. 7, 225 (2017)

28. T. Dayakar, R.V. Rao, J. Park, P. Krishna, P. Swaroopa, Y. Ji, J. Mater. Sci. Mater. Electro. 30, 9725 (2019)

29. L.S. Wang, J.C. Deng, F. Yang, T. Chen, Mater. Chem. Phys. 108, 165 (2008)

30. A. El-Trass, H. ElShamy, I. El-Mehasseb, M. El-Kemary, Appl. Surf. Sci. 258, 2997 (2012)

31. M. Elango, M. Deepa, R. Subramanian, A.M. Musthafa, Polym-Plast Technol. Eng. 57, $1440(2018)$

32. P. Kubelka, F. Munk, Z. Tech. Phys. 12, 593 (2011)

33. S. Felix, P. Kollu, A.N. Grace, Mater. Res. Innovations 29, 27 (2017)

34. S. Hsieh, P.Y. Lin, L.Y. Chu, J. Phy. Chem. C 118, 12500 (2014)

35. K. Xu, J. Wu, C.F. Tan, G.W. Ho, A. Wei, M. Hong, Nanoscale 9, 11574 (2017)

36. R. Sankar, P. Manikandan, V. Malarvizhi, T. Fathima, K.S. Shivashangari, V. Ravikumar, Spectrochim. Acta A 121, 746 (2014) 
37. M.G. Méndez-Medrano, E. Kowalska, A. Lehoux, A. Herissan, B. Ohtani, D. Bahena, V. Briois, C. Colbeau-Justin, J.L. Rodríguez-López, H. Remita, J. Phys. Chem. C 120, 5143 (2016)

38. T.I. Shaheen, M.E. El-Naggar, J.S. Hussein, M. El-Bana, E. Emara, Z. El-Khayat, M.M. Fouda, H. Ebaid, A. Hebeish. Biomed. Pharmacother. 83, 865 (2016)

39. Z. Liu, W. Li, X. Li, M. Zhang, L. Shen, Y. Zheng, J. Ethonopharmacol. 145, 233 (2013)

40. N. Patel, A.K. Prajapati, R.N. Jadeja, R.N. Patel, S.K. Patel, V.K. Gupta, I.P. Tripathi, N. Dwivedi, Inorg. Chim. Acta 493, 20 (2019)

41. S.H. Back, R.J. Kaufman, Annu. Rev. Biochem. 81, 767 (2012)

42. B.L. Farah, D.J. Landau, R. A. Sinha, E.D. Brooks, Y. Wu, S. Y. Fung, T. Tanaka, M. Hirayama, B.H. Bay, D.D. Koeberl, P.M. Yen, J. Hepatol. 64, 370 (2016)

43. M.S. Müller, M. Fouyssac, C.W. Taylor, Curr. Biol. 28, 3481 (2018) 
Figures

(A)

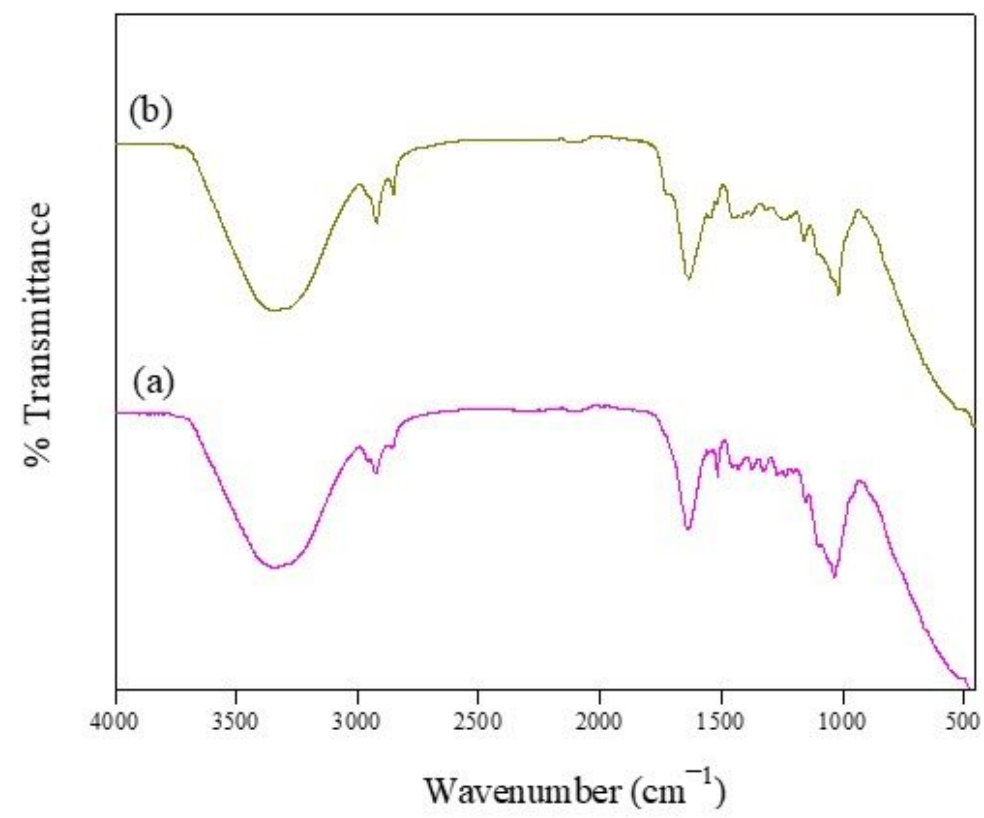

(B)

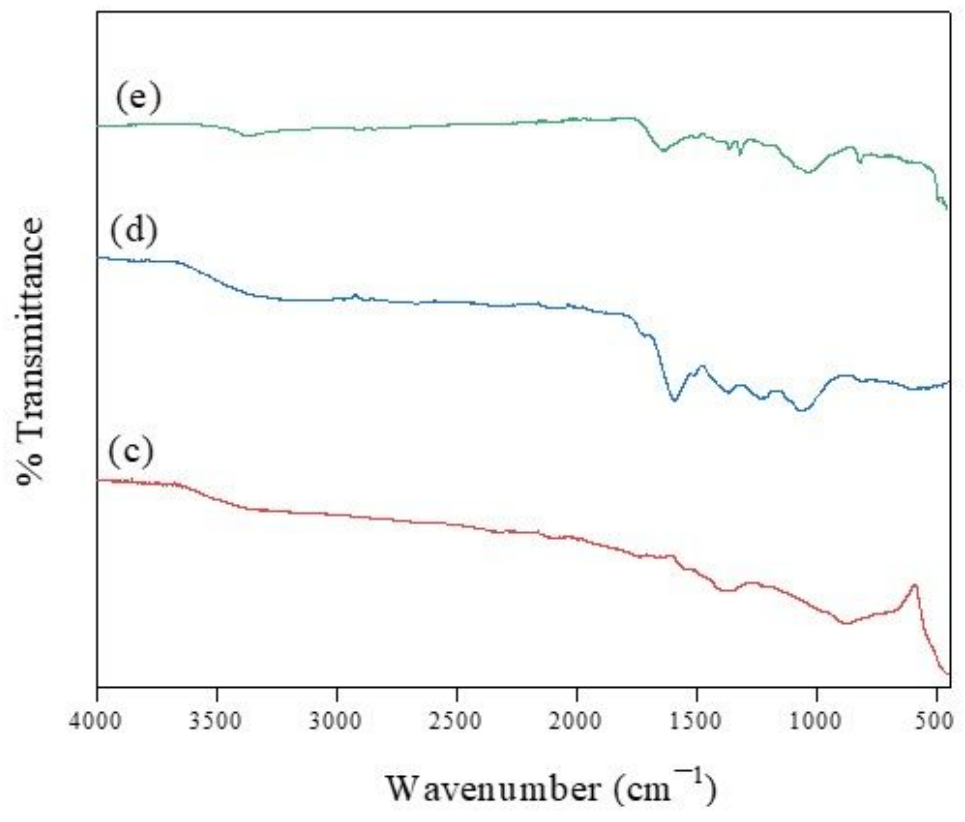

Figure 1

FT IR spectra of green extracts (A): Murraya koenigii extract (a) and Zingiber officinale extract (b), and nanomaterials (B): C1 (c), SC2 (d) and SC3 (e). 


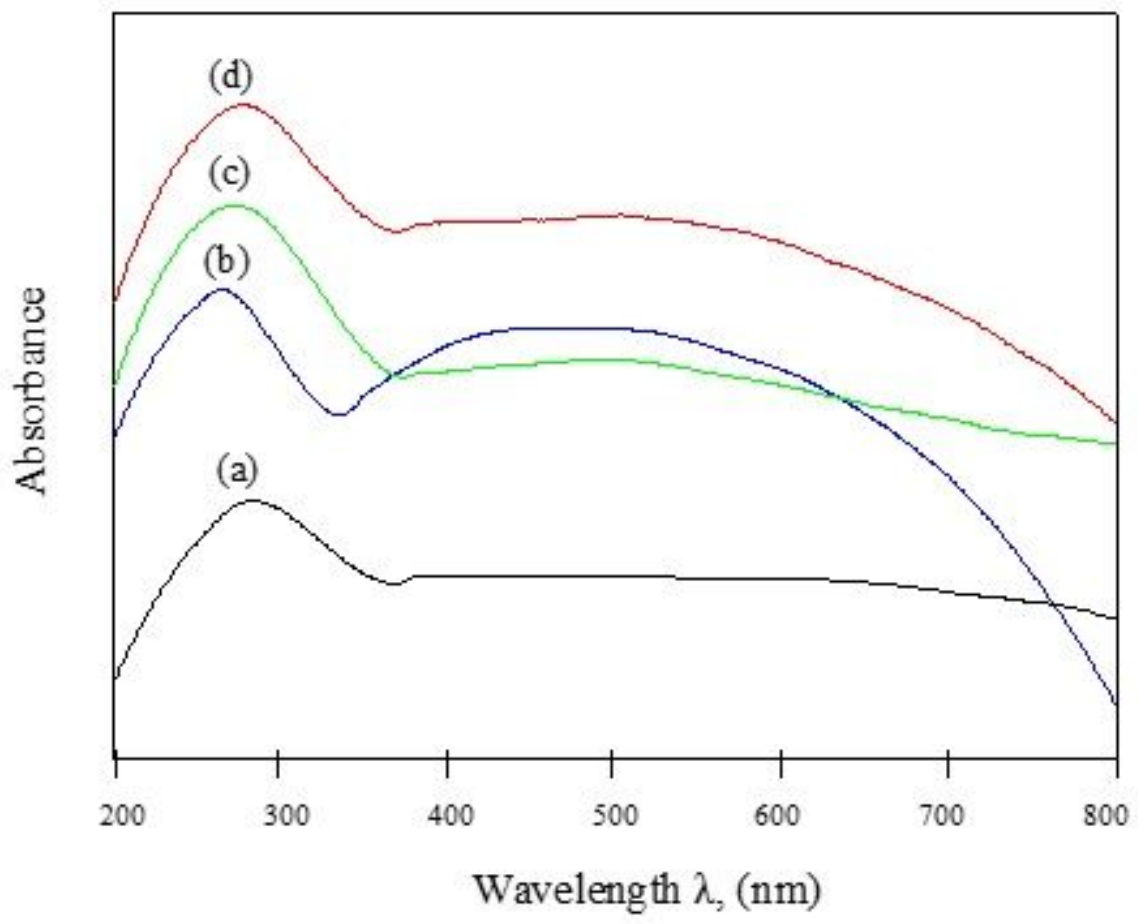

Figure 2

UV-Vis DRS spectra of C1 (a), SC1 (b), SC2 (c) and SC3 (d). 

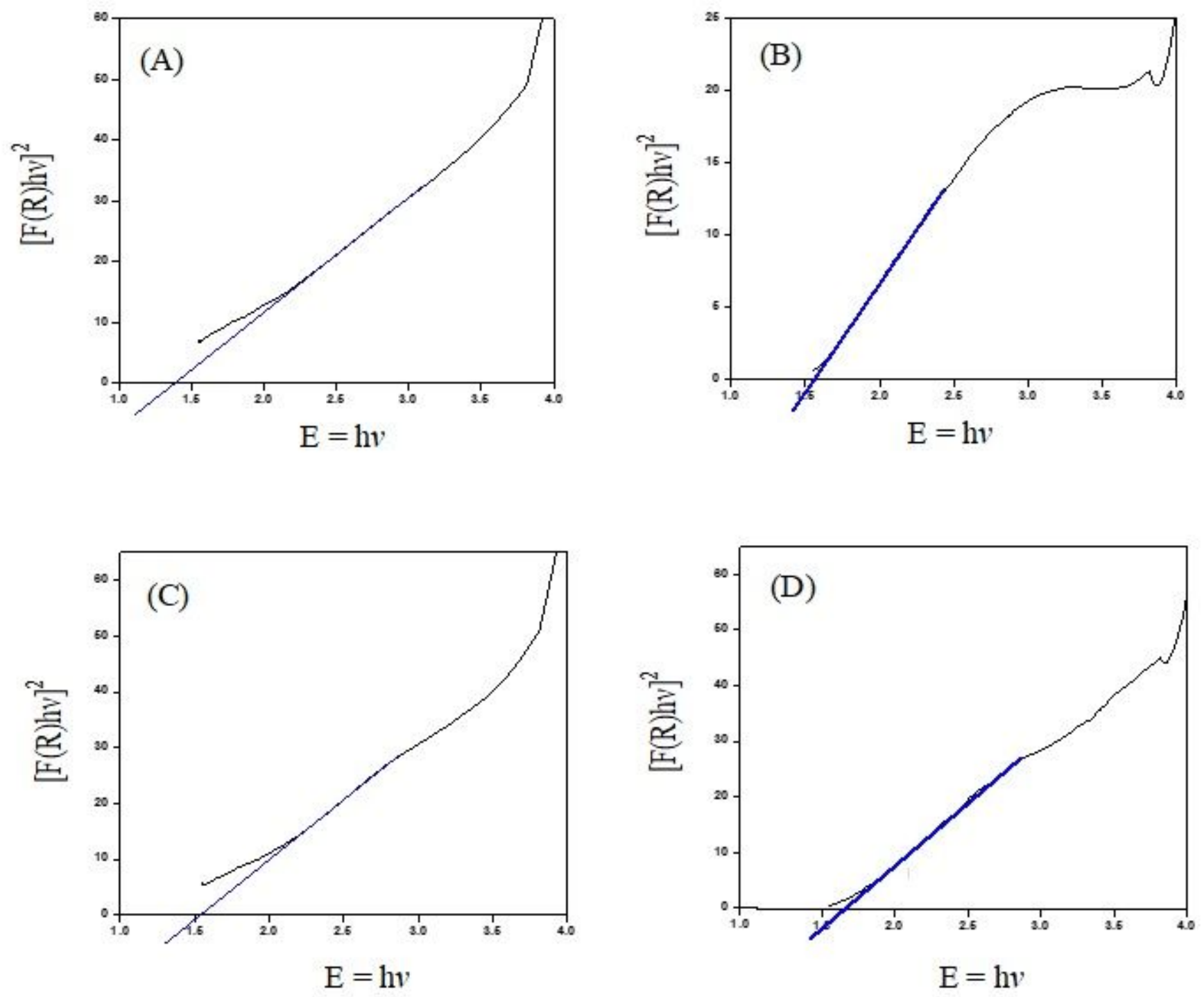

Figure 3

Estimated bandgap of C1 (a), SC1 (b), SC2 (c) and SC3 (d). 


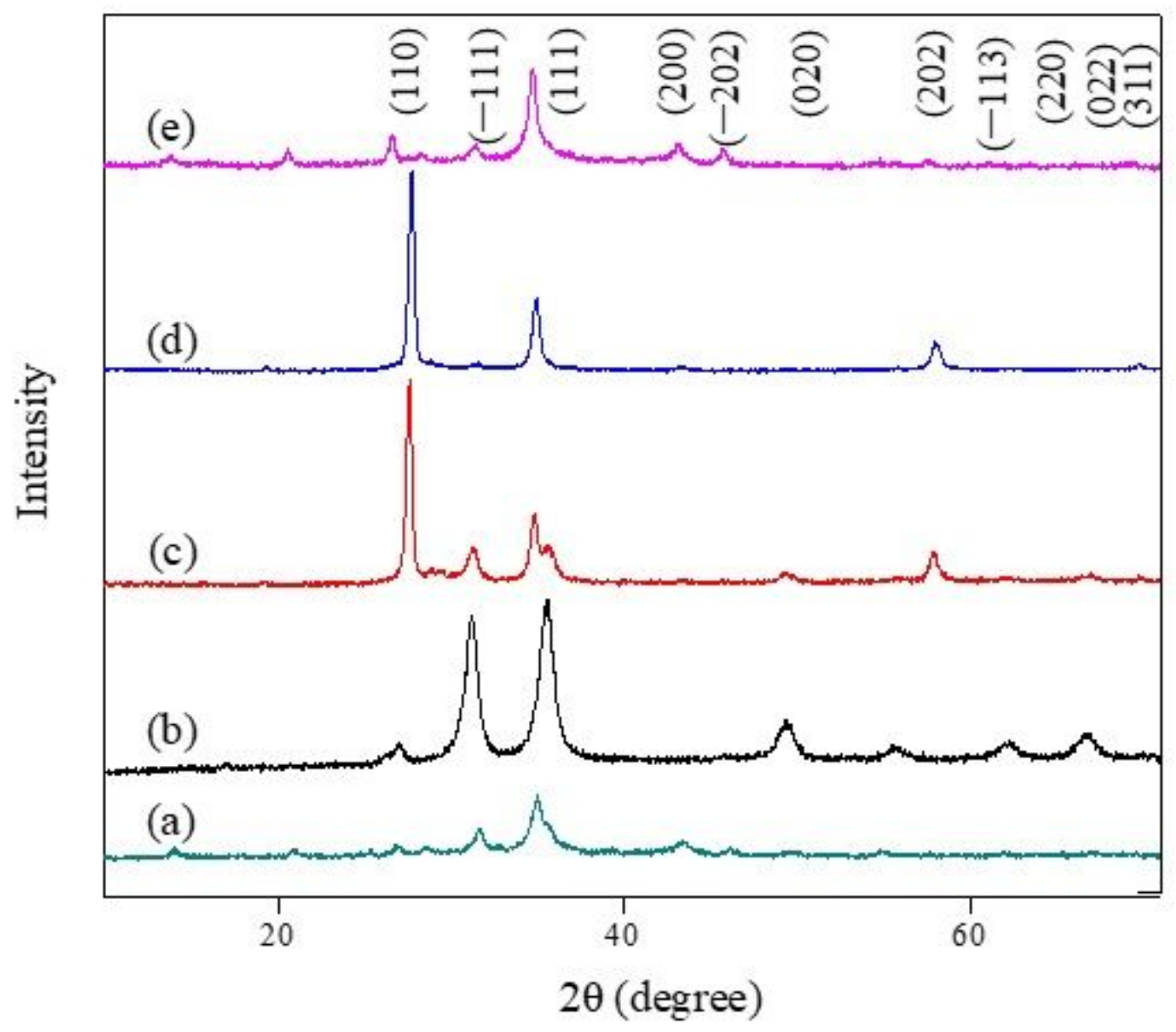

Figure 4

X-Ray diffraction patterns of S1 (a), C1 (b), SC1 (c), SC2 (d) and SC3 (e). 

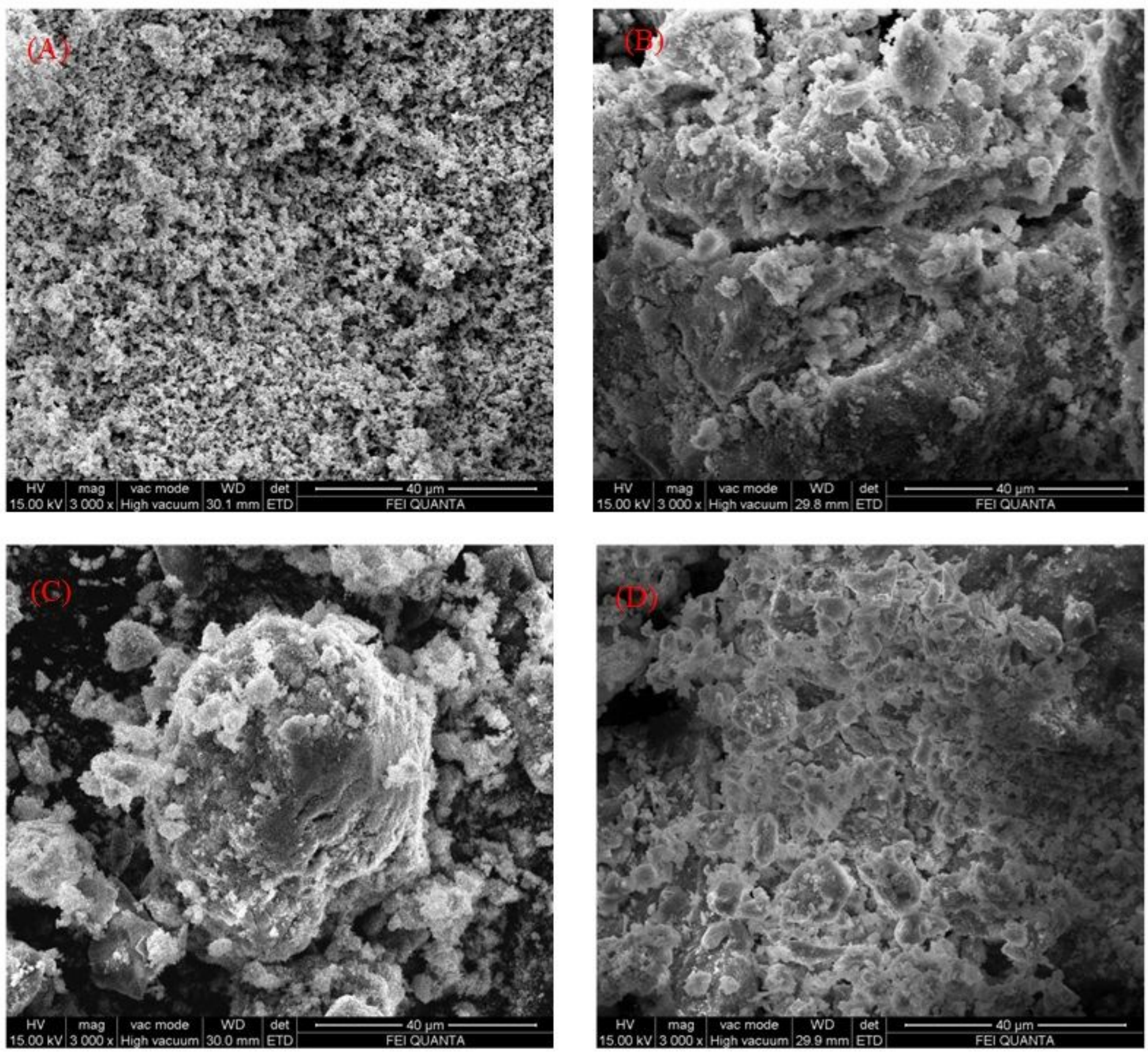

\section{Figure 5}

SEM images of nanomaterials: S1 (a), C1 (b), SC1 (c) and SC2 (d). 

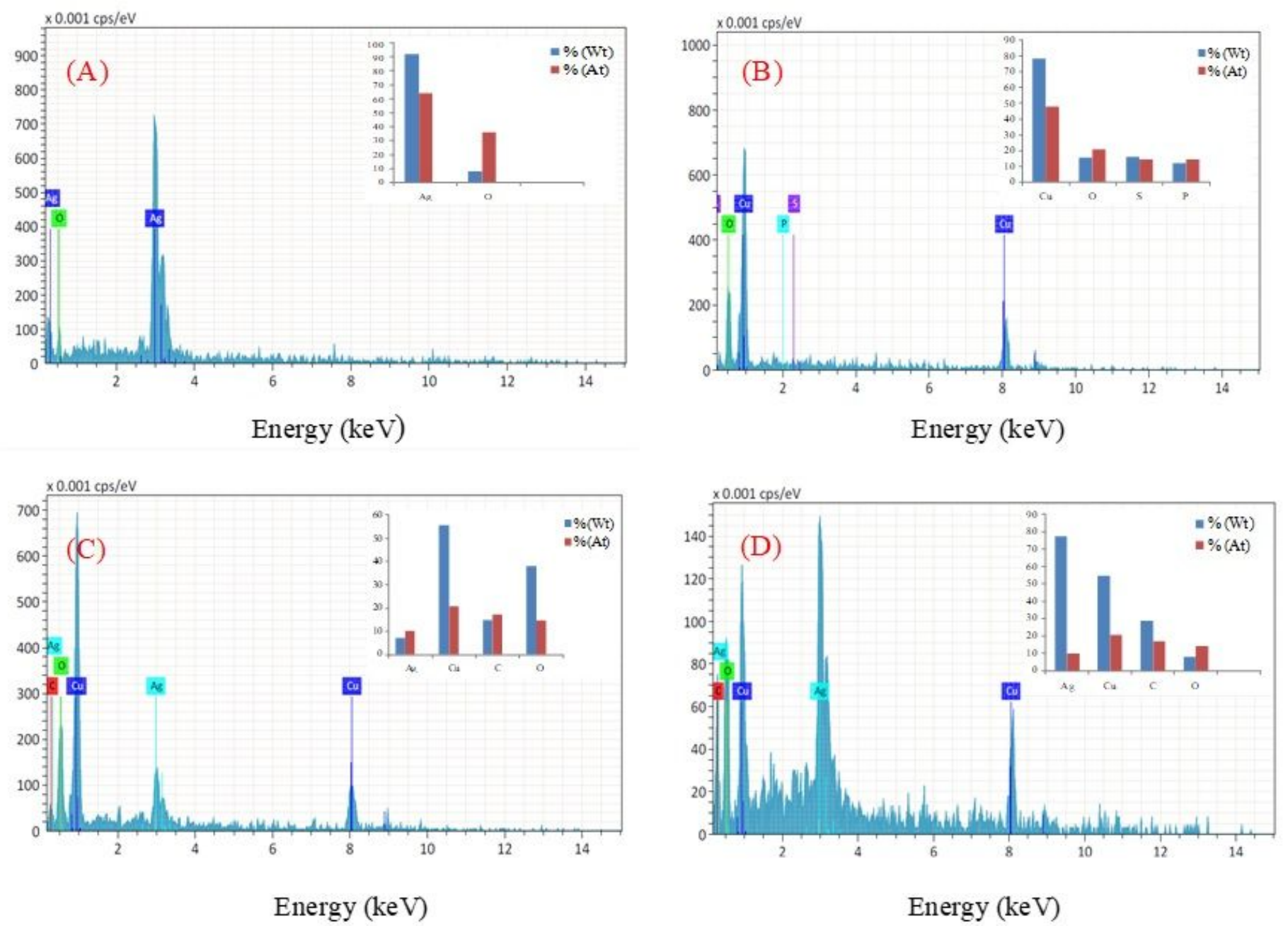

Figure 6

Energy dispersive spectra of nanomaterials: S1 (a), C1 (b), SC1 (c) and SC2 (d). 

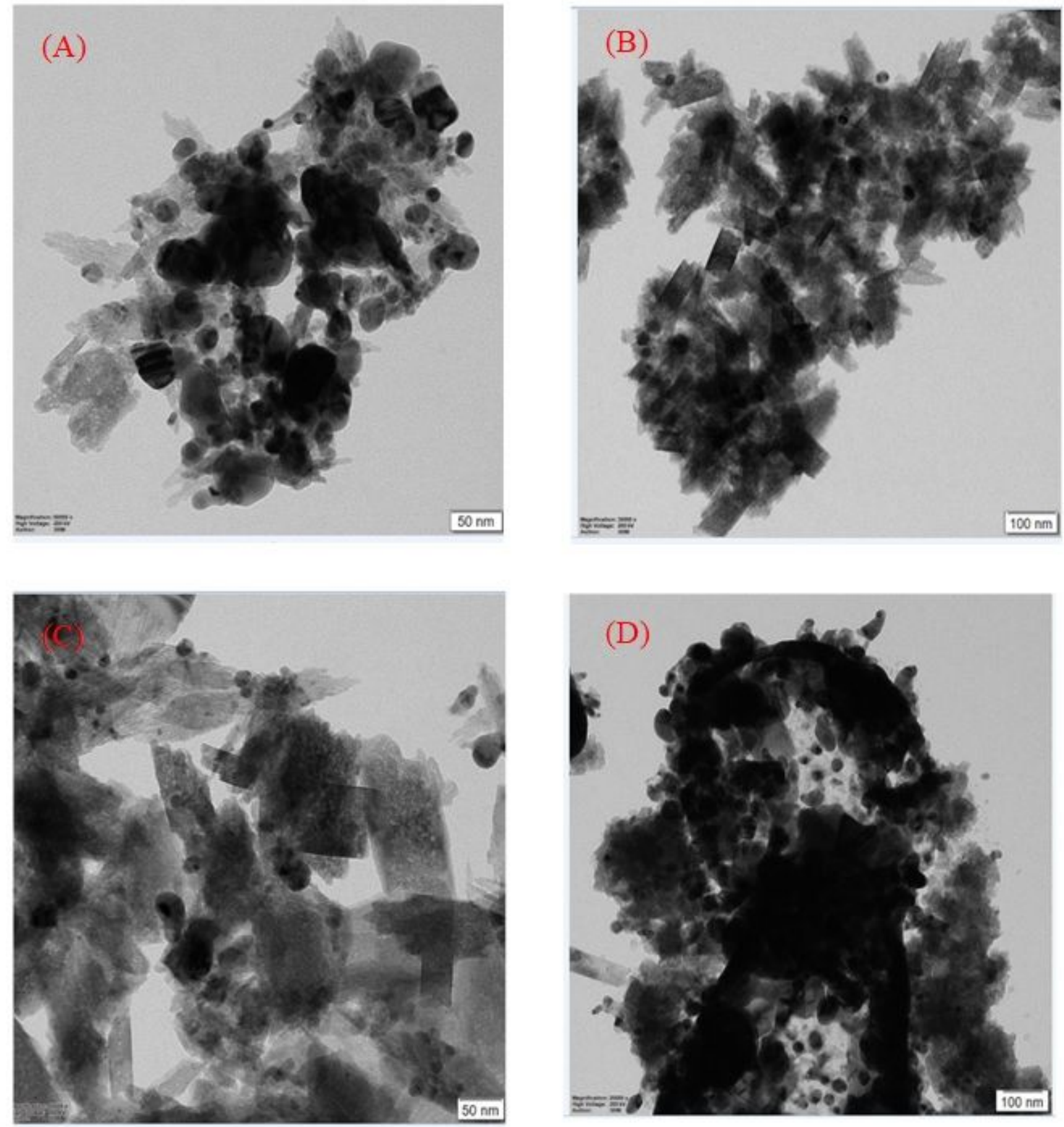

Figure 7

TEM images of nanomaterials: C1 (a), SC1 (b), SC2 (c) and SC3 (d). 


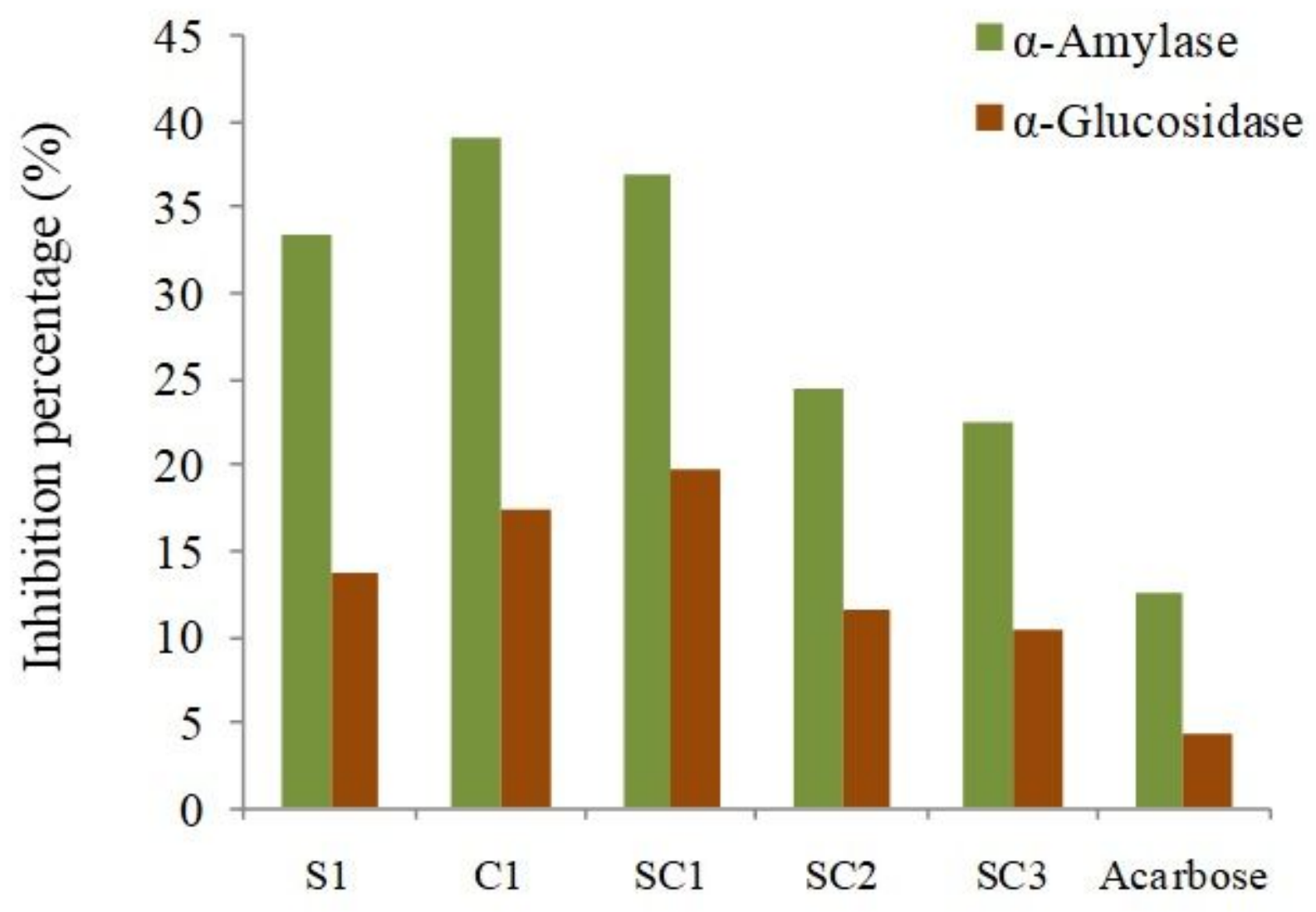

Figure 8

Percentage of a-amylase and a-glucosidse inhibitory activity of nanomaterials. 


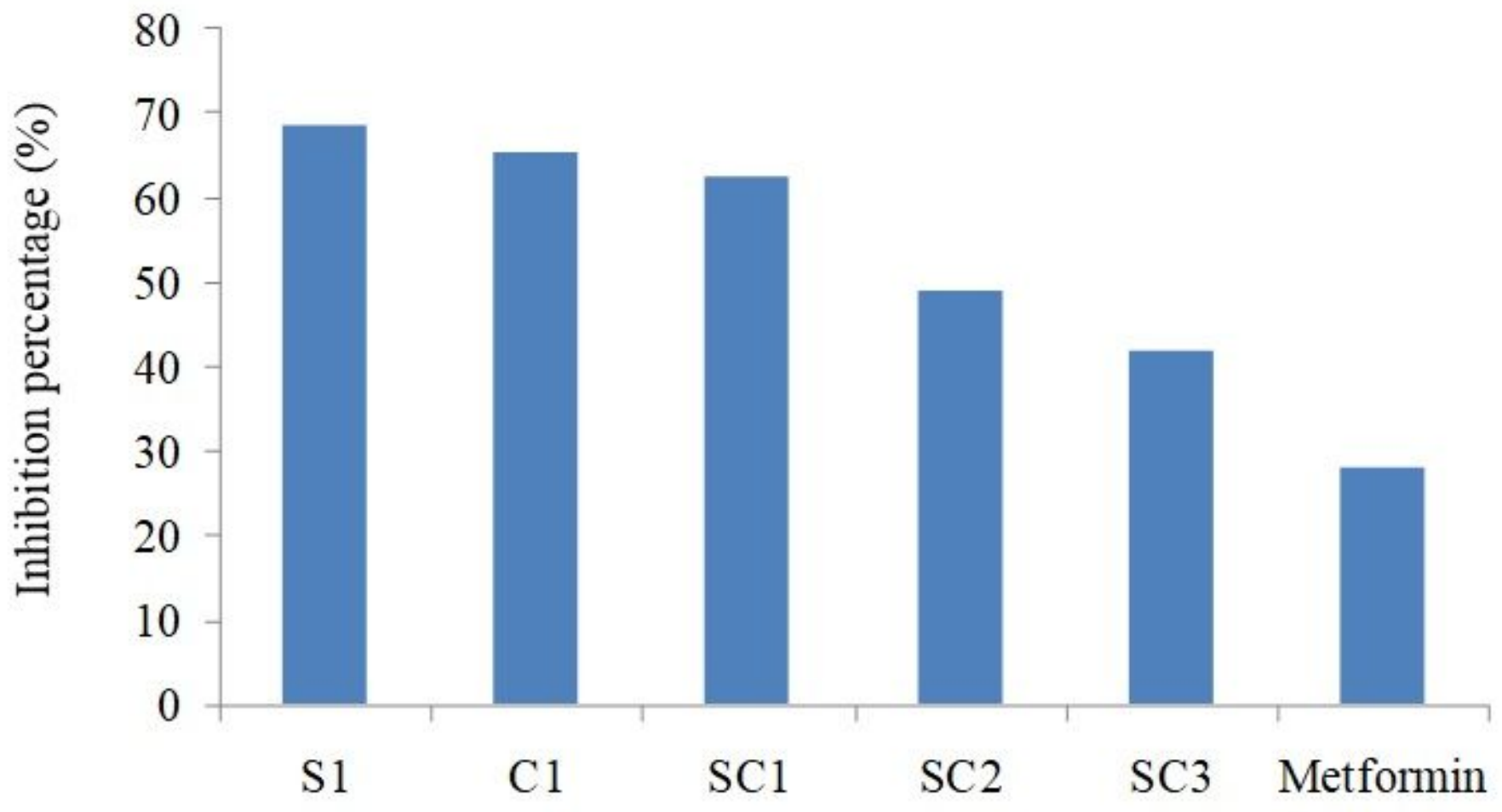

Figure 9

Bar diagram showing the inhibition of glucose-6-phosphatase enzyme by nanomaterials. 

Insulin
- Sample
- Metformin
- Inusulin + Sample
- Insulin + Metformin
Inusulin + Sample + Metformin

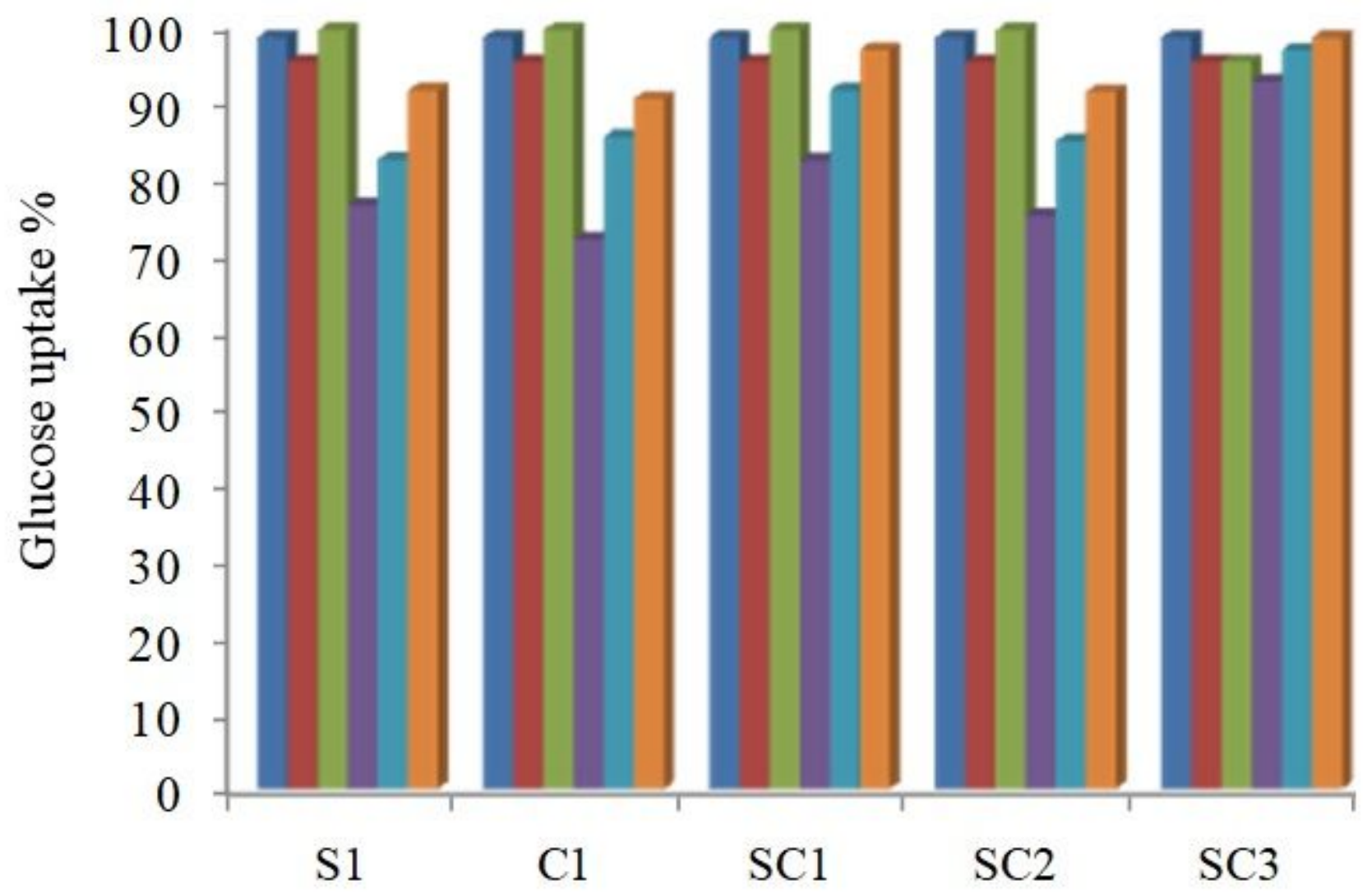

Figure 10

Effect of insulin, metformin and nanomaterials on 3T3-L1 adipocyte cells showing glucose uptake \%.

\section{Supplementary Files}

This is a list of supplementary files associated with this preprint. Click to download.

- ESIJIOMPM.docx 